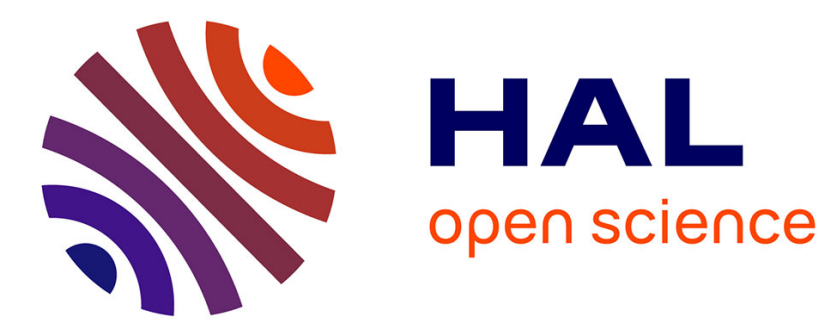

\title{
Experimental Insights on the Propagation of Fine-Grained Geophysical Flows Entering Water
} Alexis Bougouin, Olivier Roche, Raphael Paris, Herbert E Huppert

\section{To cite this version:}

Alexis Bougouin, Olivier Roche, Raphael Paris, Herbert E Huppert. Experimental Insights on the Propagation of Fine-Grained Geophysical Flows Entering Water. Journal of Geophysical Research. Oceans, 2021, 126 (4), 10.1029/2020JC016838 . hal-03192290

\section{HAL Id: hal-03192290 \\ https://hal.science/hal-03192290}

Submitted on 7 Apr 2021

HAL is a multi-disciplinary open access archive for the deposit and dissemination of scientific research documents, whether they are published or not. The documents may come from teaching and research institutions in France or abroad, or from public or private research centers.
L'archive ouverte pluridisciplinaire HAL, est destinée au dépôt et à la diffusion de documents scientifiques de niveau recherche, publiés ou non, émanant des établissements d'enseignement et de recherche français ou étrangers, des laboratoires publics ou privés. 


\title{
Experimental insights on the propagation of fine-grained geophysical flows entering water
}

\author{
Alexis Bougouin ${ }^{1}$, Olivier Roche ${ }^{1}$, Raphaël Paris ${ }^{1}$ and Herbert E. Huppert ${ }^{2}$ \\ ${ }^{1}$ Université Clermont Auvergne, CNRS, IRD, OPGC, Laboratoire Magmas et Volcans, F-63000 \\ Clermont-Ferrand, France \\ ${ }^{2}$ Institute of Theoretical Geophysics, King's College, University of Cambridge, Cambridge, CB2 1ST, \\ United Kingdom
}

\section{Key Points:}

- Gas-fluidized granular flows down an inclined plane entering water are investigated experimentally and compared to those propagating in air

- The presence of the water body promotes the generation of a granular jet above the free surface and a particle-driven gravity current underwater

- The granular jet and the current are well described by ballistic motion theory and the physics of gravity currents, respectively

Corresponding author: A. Bougouin, alexis.bougouin@univ-lehavre.fr 


\begin{abstract}
Granular flows that propagate down a mountainside, then reach the sea, a lake or a river and finally, travel underwater, is a common event on the Earth's surface. To help the description of such events, laboratory experiments on gas-fluidized granular flows entering water are performed, analyzed, and compared to those propagating in air. The originality of this study lies in the fluidization process, which improves the laboratory modelling of geophysical flows by taking their high mobility into account. Qualitatively, the presence of the water body promotes the generation of a granular jet over the water surface, a leading and largest wave, and a particle-driven gravity current underwater. Hydrodynamic forces mainly play a dissipative role by slowing and reducing the spreading of the granular mass underwater, but a low amount of grains are still transported by the turbulent fluid as a gravity current far away. The temporal evolution of the granular jet and the particle-driven gravity current are well described by ballistic motion theory and scaling laws of homogeneous gravity currents, respectively. Most currents propagate with a constant flow-front velocity along the horizontal bottom, which is controlled by the flow height depending on the water depth. In constrast, the bulk volume concentration of particles in the current is estimated to be nearly constant, interpreted as a critical concentration above which the excess of particles cannot be maintained by the turbulent fluid. This experimental study highlights the complexity of the dynamics and deposits of granular masses when they encounter a water body.
\end{abstract}

\title{
Plain Language Summary
}

Geophysical granular flows driven by gravity occur frequently on the Earth's surface, as a result of climatic, tectonic or volcanic events. When they occur near the sea, a lake or a river, the granular flows may enter water, generate tsunamis, and propagate underwater. This study presents laboratory experiments on gas-fluidized granular flows entering water, which are performed in a $7 \mathrm{~m}$-long channel and recorded by high-speed cameras. The fluidization process ensures dynamic similarity for modelling of highly mobile geophysical flows composed of fine materials, which are predisposed to reach the coast and generate turbidity currents underwater. The main contributions of this study are summarized as follows: (i) we show that fine-grained flows entering a water body generate both a granular jet over the water surface and a particle-driven gravity current underwater; (ii) we highlight the dissipative role of water in slowing and reducing the spreading of the granular mass underwater, while a low amount of grains is still transported as a gravity current far away; and (iii) we describe the dynamics of the granular jet and gravity current using simple theoretical models including major physical processes.

Keywords: laboratory experiments, granular media, fluidization process, geophysical flows, gravity currents, tsunamis.

\section{Introduction}

Geophysical granular flows driven by gravity occur frequently on the Earth's surface, as a result of climatic, tectonic, or volcanic events (Delannay et al., 2017). Granular flows contribute significantly to the global sediment cycle and the shape of landscapes. When they occur near the sea, a lake or a river, these solid-fluid mixtures may enter water, generate tsunamis, and propagate underwater (Løvholt et al., 2015). The subaqueous flows are known to be more highly mobile compared to subaerial flows and they may cause severe damage to submarine facilities (De Blasio et al., 2006). To predict their potential impact offshore, it is essential to understand the flow dynamics of subaerially-initiated granular flows after impacting water.

Many field observations reported the situation of submarine landslides evolving to turbidity currents (e.g., Heezen \& Ewing, 1952, 1955; Mulder et al., 1997; Talling et al., 
2007; Hsu et al., 2008). There are different ways to define these currents, but they broadly consist of very dilute particle-laden flows in which grains are mainly suspended by the turbulent water (Kneller \& Buckee, 2000). In some cases, the dilute clouds can overlay dense near-bed layers, as recently shown by field measurements (Paull et al., 2018; Simmons et al., 2020; Wang et al., 2020). It is more difficult to find such reports about the transformation of a subaerial granular mass after entering water, because interest has mainly focused on the wave generation (e.g., Weiss et al., 2009). However, it is expected that granular flows composed of fine materials (e.g., fine-grained landslides, ash-rich pyroclastic flows) are particularly predisposed to generate subaqueous turbidity currents when they enter water because particles have low settling velocity and they can be easily suspended by the turbulent water. To the best of our knowledge, such an event has never been observed and only field works on volcaniclastic deposits have discussed turbidity currents formed by pyroclastic flows entering water. During the 12-13 July 2003 paroxysmal dome collapse of Soufrière Hills volcano, more than $200 \times 10^{6} \mathrm{~m}^{3}$ of hot pyroclastic material entered the ocean. Phreatic explosions were observed and a cloud surge, decoupled from the main flow, travelled 2 to $3 \mathrm{~km}$ over the water surface (Edmonds \& Herd, 2005). This phreatic activity promoted the ingestion of sea water by the pyroclastic flow that evolved as a cool and dense water-saturated granular flow underwater (Trofimovs et al., 2008). Additionally, a grain-size sorting process occurred within the subaqueous flow, which led to a fine-particle overload in the upper part and the formation of distal turbidity currents that propagated for more than $30 \mathrm{~km}$ on gentle slopes of the sea floor (Trofimovs et al., 2006, 2008). Similar transformation of a subaerially-initiated pyroclastic flow into a subaqueous turbidity current was proposed by Whitham (1989) for explaining Roseau Ash submarine deposits (Dominica Island, Lesser Antilles). The volcaniclastic turbidite deposit was found up to $250 \mathrm{~km}$ from the source, at $3000 \mathrm{~m}$ water depth. Cas and Wright (1991) reported the possible scenarios when hot pyroclastic flows interact with the sea, and most of them highlight the formation of turbidity currents.

Most experimental studies on granular masses entering water considered dry, heavy, and coarse grains leading to dense granular flows depositing rapidly underwater (e.g., Fritz et al., 2003b; Viroulet et al., 2014; Miller et al., 2017). The generation of particledriven gravity currents by initially-subaerial fine-grained flows has therefore been poorly investigated. Mcleod et al. (1999) first considered different grain-fluid mixtures, initially maintained above the free-surface and released over an inclined plane, which entered fresh water. They concluded that both negatively and positively buoyant gravity currents can be obtained separately or together, by varying the grain and fluid densities of the mixture. These different flow dynamics have also been reported for homogeneous gravity currents released into a two-fluid layer (Monaghan et al., 1999; Legros \& Druitt, 2000; Monaghan, 2007; Wells \& Wettlaufer, 2007; Cortés et al., 2014). Freundt (2003) focused on the thermal effects of volcanic ash heated up to $400^{\circ} \mathrm{C}$, entering water at ambient temperature. Steam explosions and major ash-cloud surges propagating above the water surface were obtained with increasing temperature. By contrast, the dynamics of particledriven gravity currents was mainly controlled by the mass flux of the granular flow and the water depth, while it was not significantly affected by the temperature. In fact, heat transfers mainly modified the early stages of the gravity currents, which propagated dominantly along the water surface at high temperature. Despite these studies, there is still a lack on the description of the granular dynamics after such flows enter water, which is the focus of the present study.

Most works on the propagation of particle-driven gravity currents considered simple configurations using laboratory experiments, numerical simulations and theoretical descriptions. One of the most famous configurations corresponds to the propagation of a fixed volume of a heavy fluid released into a lighter fluid on a horizontal plane, the socalled lock-exchange problem (e.g., Huppert \& Simpson, 1980; Huppert, 1982; Rottman \& Simpson, 1983). In this case, the motion of homogeneous gravity currents is driven by the density difference between the current and the surrounding fluid. Depending on 
the dominant forces, the flow dynamics of the current in the two-dimensional configuration is usually described in three distinct stages, well predicted by shallow layer/lubrication models: (i) a slumping regime dominated by inertia during which the flow-front velocity remains constant; (ii) an inertial self-similar regime characterized by a buoyancy/inertia balance for which the front position scales with time as $x_{f} \propto t^{2 / 3}$; and (iii) a viscous regime controlled by a balance between buoyancy and viscous dissipation in which the front evolves as $x_{f} \propto t^{1 / 5}$ (Huppert \& Simpson, 1980; Huppert, 1982; Rottman \& Simpson, 1983). This configuration has been extended to gravity currents propagating down an inclined plane, for which the gravity current is described by an acceleration phase followed by a deceleration phase (e.g., Beghin et al., 1981; Monaghan et al., 1999; Dai \& Garcia, 2010; Dai, 2013, 2014). When the current decelerates, the front position scales as $x_{f} \propto t^{2 / 3}$ or $x_{f} \propto t^{1 / 2}$ according to the preponderance of inertia or viscous effects, respectively (Dai, 2014). The motion of these gravity currents is also well predicted by the thermal theory based on the mass and momentum conservation by considering the entrainment of the ambient fluid (Beghin et al., 1981). Finally, for gravity currents down an inclined plane produced by a continuous inflow, the currents evolve with a constant front velocity depending mainly on the buoyancy flux, while the effect of the slope angle is unsignificant (e.g., Britter \& Linden, 1980; Baines, 2001, 2005). We recall that other simple configurations have also been considered, in which the above-mentioned stages were observed despite a modification of the scaling laws (e.g., Huppert, 1982; Zgheib et al., 2015; Zhu et al., 2017). The particle-driven gravity currents are fundamentally gravity currents whose density is greater than that of the surrounding fluid because of their suspended grains (Meiburg \& Kneller, 2010; Wells \& Dorell, 2020). However, the flow dynamics of these currents are more complex than those of homogeneous gravity currents, i.e. the intrusion of a pure fluid into another fluid, because the particle concentration evolves with time and position due to the erosion/deposition of grains (e.g., Bonnecaze et al., 1993, 1995).

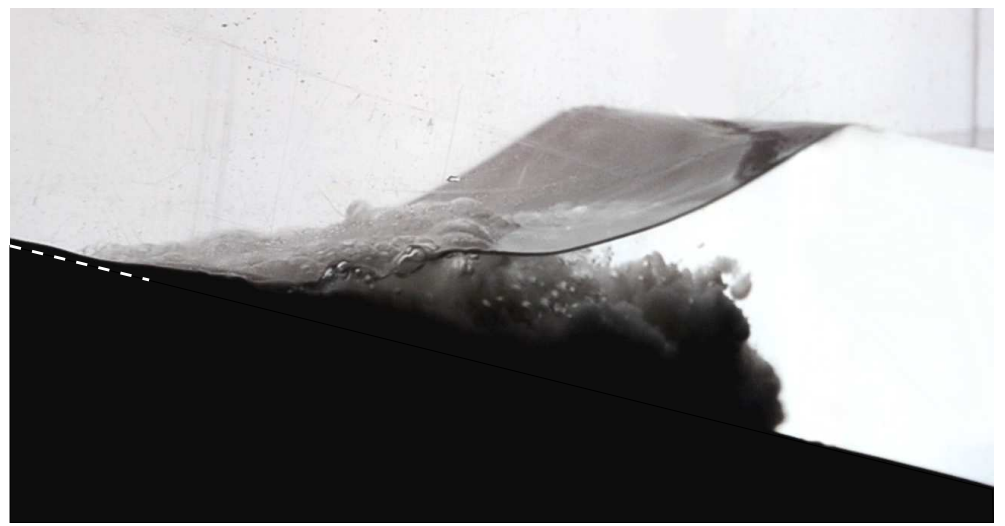

Figure 1. Oblique view of a particle-driven gravity current, generated by a gas-fluidized granular flow down an inclined plane entering water. The dashed line indicates the bottom of the inclined plane above the level of the undisturbed water surface. On the left, the subaerial granular flow is relatively thin, dense and rapid before evolving to a thick and dilute particle-driven gravity current underwater. An impulse wave is also generated on the water surface, which has already been studied in Bougouin et al. (2020).

In the present work, laboratory experiments on gas-fluidized granular flows entering a body of water are performed to understand better the dynamics of geophysical flows after they reach the sea, a lake or a river. More specifically, it focuses on granular flows composed of fine materials, which are predisposed to generate particle-driven gravity cur- 
rents underwater, as illustrated by the oblique view of Figure 1. The questions raised in the present contribution are the following. What is the effect of a water body on the propagation of subaerially-initiated fine-grained flows along an inclined plane? Does the water body play a dissipative or a driven role on the granular material? Can the general evolution of the granular material be described using simple theoretical models? In order to provide some answers, the paper is organized as follows. In Sec. 2, the experimental setup and materials used are presented. Sec. 3 highlights the influence of the presence of a water body on the granular dynamics through qualitative observations and a comparison between gas-fluidized granular flows propagating only in air and entering water. Finally, the evolution of the granular material, i.e. the initial granular jet above the water surface and the particle-driven gravity current underwater, is described using theoretical models (Secs. 4 and 5).

\section{Experimental setup}

\subsection{Apparatus}

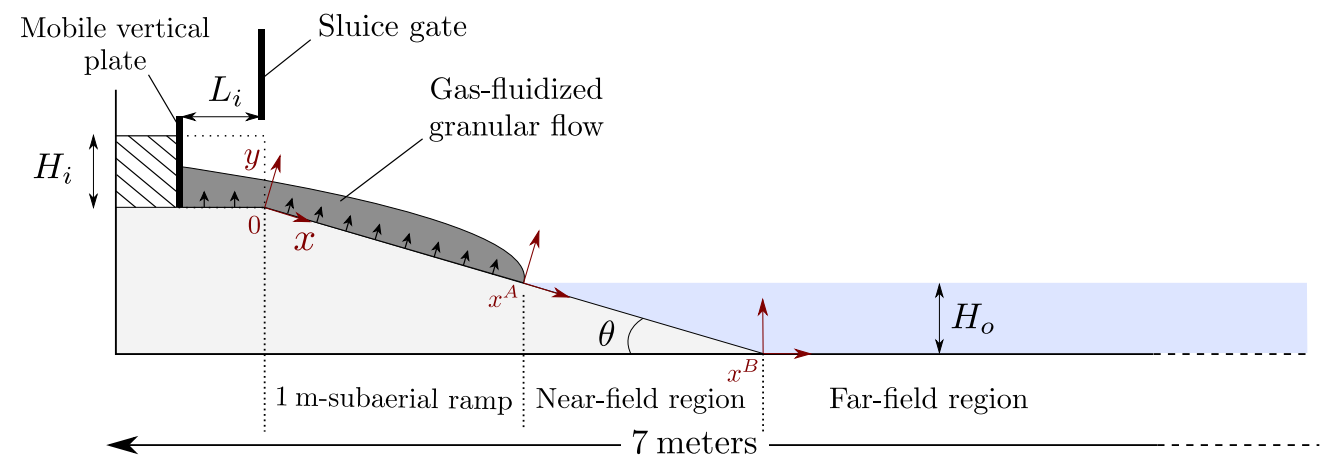

Figure 2. Sketch of the experimental setup with the initial parameters (the height $H_{i}$ and the length $L_{i}$ defining the initial dimensions of the granular column, the slope angle $\theta$ of the inclined plane, and the water depth $H_{o}$ ). Black arrows represent the air flux through the $12 \mu$ m-porous bottom plane for the fluidization process. The streamwise coordinates $x^{A}$ and $x^{B}$ indicate the transition from the $1 \mathrm{~m}$-subaerial ramp to the immersed ramp, and the end of the inclined plane that connects to the horizontal bottom, respectively. The zones containing the immersed inclined plane and the horizontal bottom are referred to as the near- and far-field regions, respectively.

Laboratory experiments are conducted in a horizontal transparent channel of rectangular cross-section with dimensions of $7 \times 0.8 \times 0.2 \mathrm{~m}^{3}$ in the longitudinal, vertical and spanwise directions, respectively. A sketch of the experimental setup is given in Figure 2. One side of the channel is equipped with a reservoir delimited by a sluice gate and a mobile vertical plate to vary the initial length $L_{i}$ of the granular column. In this study, the length and the height of the initial granular column are varied in the range $L_{i}=$ $[9: 34] \pm 0.5 \mathrm{~cm}$ and $H_{i}=[10: 42] \pm 0.5 \mathrm{~cm}$, respectively. The reservoir is connected to an inclined plane composed of a $1 \mathrm{~m}$-subaerial ramp and an immersed ramp. Both the bottom of the reservoir and of the $1 \mathrm{~m}$-subaerial ramp are equipped with a $12 \mu \mathrm{m}$ porous plate to fluidize the granular flow by a vertical air flux before entering water (see black arrows, in Figure 2). Here, the granular material is fluidized with an air velocity of $U_{f} \sim 4.7 \pm 0.1 \mathrm{~mm} . \mathrm{s}^{-1}$, larger than the minimum fluidization velocity $U_{m f} \sim 3.8 \pm$ $0.1 \mathrm{~mm} . \mathrm{s}^{-1}$, which ensures that the granular flow is fully fluidized when it impacts water. The minimum fluidization velocity $U_{m f}$ is estimated prior the experiments as the minimum velocity for which the gas pore pressure counterbalances the pressure of a static 
granular column. The length of the immersed ramp varies as $H_{o} / \sin \theta$, where the slope angle is set to $\theta=5^{\circ}, 10^{\circ}, 15^{\circ}, 20^{\circ}$, and $30^{\circ}$ and the water depth is varied up to $H_{o}=$ $38.5 \pm 0.1 \mathrm{~cm}$. In the following, the zones containing the immersed ramp and the horizontal bottom are referred to as the near- and far-field regions, respectively. On the opposite side of the channel, a wave breaker is used to limit the reflected waves, which could affect the granular flow dynamics underwater. Indeed, the wave velocity is still much larger than that of the particle-driven gravity current.

As discussed by Bougouin et al. (2020), the initial conditions of the experiment control the flow parameters, namely the volume, the velocity, and the height of the granular flow. The volume per unit width is estimated as $v=\left(H_{i}-h_{r}\right) L_{i}$, where $h_{r}$ is the residual height of grains in the reservoir at the end of the experiment. The height profile of the granular flow is non-uniform along the inclined plane, and the front-height $h_{f}$ at the impact is therefore chosen as the flow height at $10 \mathrm{~cm}$ behind the front (more information is provided in the Bougouin et al. (2020)'s Supporting Information). The constant front velocity $u_{f}$ of fluidized granular flows is estimated at the impact, from the slope of the linear trend between the front position and time. Finally, as both $h_{f}$ and $u_{f}$ vary together with $H_{i}$, the flow rate per unit width $q=h_{f} u_{f}$ is also defined. In this study, the control parameters are varied in the range $v=[1.5: 13.2] \pm 0.1 \mathrm{dm}^{2}$ (with $\left.1 \mathrm{dm}^{2}=10^{-2} \mathrm{~m}^{2}\right), h_{f}=[0.9: 2.8] \pm 0.4 \mathrm{~cm}, u_{f}=[2: 3.7] \pm 0.1 \mathrm{~m} . \mathrm{s}^{-1}$, and $q=[1.8:$ $8.5] \pm 1 \mathrm{dm}^{2} \cdot \mathrm{s}^{-1}$, respectively.

At the initial time $t=0$, the sluice gate is rapidly and entirely removed with a velocity of about $2 \mathrm{~m} . \mathrm{s}^{-1}$ by releasing a suspended weight, which triggers the collapse of the granular column on the inclined plane. The flow dynamics of the granular material is recorded using a classical shadowgraph method with two Photron Fastcam 1024× 1024 pixel cameras and LED panels on the back side of the channel. This optical method allows vizualization of the interface between fluids due to different light absorptions. Here, the granular material, the water layer, and the ambient air are represented in black, gray and white, respectively (see Figure 3, for instance). The first camera records a large view of the experiment, while the second camera focuses on the flow dynamics of currents in the far-field region. The resolution obtained is $4 \mathrm{~mm} /$ pixel and $0.8 \mathrm{~mm} /$ pixel, respectively, and the acquisition rate is $250 \mathrm{~Hz}$. Finally, the extraction process is performed using a Matlab routine based on a threshold method.

\subsection{Materials}

The granular material used corresponds to quasi-monodisperse spherical glass beads manufactured by Wheelabrator, with a diameter of $d=65 \pm 10 \mu \mathrm{m}$ and a density of $\rho_{p}=2550 \pm 50 \mathrm{~kg} \cdot \mathrm{m}^{-3}$, respectively. Before each experiment, the grains are weighted, poured into the reservoir, fluidized and then the height of the initial column is measured. The particle concentration of the initial granular column is $\phi_{i}=V_{\text {grains }} / V_{\text {column }} \sim$ $0.56 \pm 0.01$, where $V_{\text {grains }}$ and $V_{\text {column }}$ denote the volume of grains and the total volume of the initial column, respectively. This corresponds to an initial bulk density of $\rho=$ $\phi_{i} \rho_{p}+\left(1-\phi_{i}\right) \rho_{a} \sim 1400 \mathrm{~kg} . \mathrm{m}^{-3}$, where $\rho_{a} \sim 1.2 \mathrm{~kg} . \mathrm{m}^{-3}$ is the density of ambient air. Both the particle concentration and the density are expected to remain constant in the reservoir and during the flow propagation on the $1 \mathrm{~m}$-subaerial ramp because of the sustained gas flow from the bottom.

Some experiments of dense liquid flows entering water are also performed to compare the propagation of homogeneous gravity currents with that of particle-driven gravity currents. Sodium Chloride $(\mathrm{NaCl})$ is therefore added to dyed water with a concentration of $325 \mathrm{~g} / \mathrm{kg}$ of water, leading to a dense saline liquid of $\rho \sim 1200 \mathrm{~kg} \cdot \mathrm{m}^{-3}$ measured by a DMA 35 Anton Paar electronic densimeter. In Sec. 5, we will show that the density of homogeneous gravity currents is roughly similar to that of particle-driven gravity currents, and their dynamics can therefore be compared together depending on the 
flow conditions at the impact. It should be remembered that no gravity currents would be generated by the entrance of a fluid into another fluid of the same density (Bullard et al., 2019; Clous et al., 2019), while reversing buoyancy of currents would be observed with a lighter fluid into a heavy fluid (Monaghan et al., 1999; Monaghan, 2007). For dense liquid flows, the initial parameters are $H_{i}=[16: 40] \mathrm{cm}, L_{i}=34 \mathrm{~cm}, H_{o}=26.4$ $\mathrm{cm}$ and $\theta=15^{\circ}$, while the flow parameters at the impact are found in the range $v=$ $[5.2: 12.5] \mathrm{dm}^{2}, u_{f}=[2.4: 3.2] \mathrm{m} . \mathrm{s}^{-1}, h_{f}=[0.9: 2.5] \mathrm{cm}$, and $q=[2.2: 8.0]$ $\mathrm{dm}^{2} \cdot \mathrm{s}^{-1}$.

\subsection{Scaling issues of geophysical granular flows}

In this section, we propose to discuss the relevance and limitations of the experiments, which aim to help the understanding of fine-grained geophysical flows propagating down a mountainside, entering the sea, a lake or a river, and then propagating underwater far away.

The novelty of this study lies in the consideration of gas-fluidized granular flows, which ensures a more suitable modelling of geophysical flows taking their high mobility into account. Indeed, natural granular flows are known to exhibit energy dissipation lower than at the laboratory scale, for which several physical mechanisms have been proposed, i.e. basal lubrication (e.g., Bowden \& Hughes, 1939; Shreve, 1968; Goren \& A., 2007), acoustic or mechanical fluidization (e.g., Melosh, 1979; T. R. H. Davies, 1982; Collins \& Melosh, 2003), high gas pore pressure (e.g., Major \& Iverson, 1999; Sparks, 1976), dynamic fragmentation (e.g., T. R. Davies \& McSaveney, 2009), and material entrainment (e.g., Hungr \& Evans, 2004; Sovilla et al., 2006), among others. At the laboratory scale, a granular flow fluidized at the source propagates faster and farther than a non-fluidized granular flow with the same initial conditions (Roche et al., 2008). In case of fluidization along the flow path and for gentle slopes, the fluidization process also prevents the deposition of grains along the bottom plane, and the entire volume of the granular flow thus enters water (Bougouin et al., 2019). This behavior is attributed to the high gas pore pressure generated by the fluidization process, which reduces the internal friction within granular flows and therefore promotes the high mobility. The dynamics of experimental and natural granular flows can be compared through the Froude number $\mathrm{Fr}=$ $u_{f} /\left(g h_{f}\right)^{1 / 2}$, which is found in the range $F r=[6: 9]$ corresponding to the upper range of natural flows (Delannay et al., 2017). Moreover, the bulk flow to water density ratio is about $\rho / \rho_{f} \sim 1.4$ which is consistent with that of most natural flows (Delannay et al., 2017), even if ash-rich pyroclastic flows and dry snow avalanches may be less dense than water. This experimental configuration seems therefore to be a relevant modelling for investigating most geophysical granular flows entering water, despite some limitations.

In the present configuration, the fluidization process is facilitated using fine, spherical, and monodisperse beads, which is a crude assumption about natural flows usually composed of different grain sizes, densities, and shapes. In this way, some physical mechanisms such as the grain-size sorting process in or out of the water, the reversing buoyancy and the coarse grain spreading underwater cannot be reproduced here. The grain size to flow length ratio of natural flows cannot also be maintained at the laboratory scale, because the grain size used in the experiments is usually similar to those found in the field. Moreover, natural pyroclastic flows can have high temperatures up to 500-600 when they enter the sea. Freundt (2003) concluded that the main consequence of high temperature was the generation of phreatic explosions and major ash-cloud surges propagating over the water surface, while particle-driven gravity currents were slightly affected close to the shoreline. However, an open question still remains about the formation of welded deposits, which could not be addressed here (Sparks et al., 1980; Cas \& Wright, 1991; Kokelaar \& Busby, 1992). In summary, the present setup ensures a suitable modelling of dense, cold or moderate-heated, fine particle-rich geophysical flows entering water. 


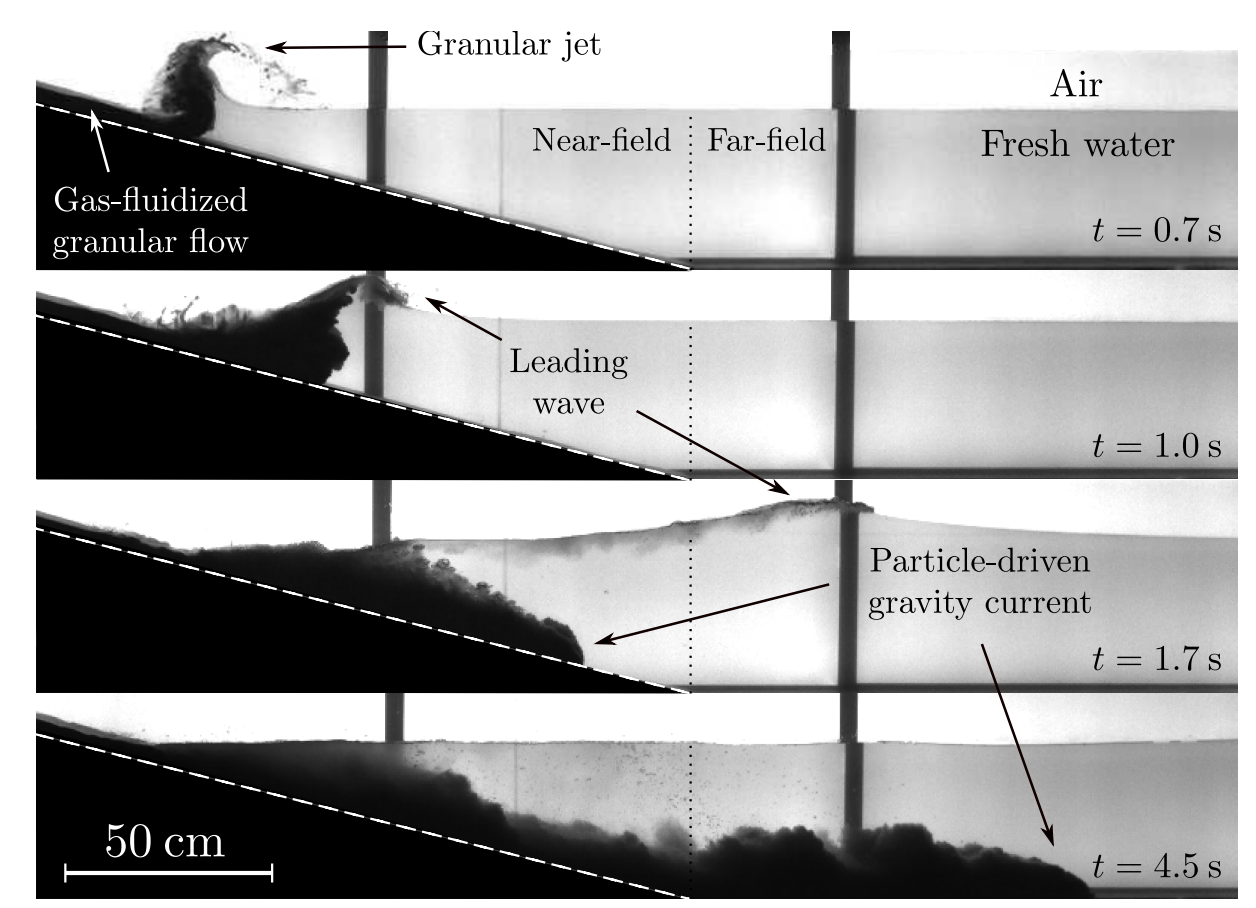

\subsection{Preliminary observations: Role of the water body}

Figure 3. Snapshots of the entrance of a gas-fluidized granular flow into water, for $H_{i}=22$ $\mathrm{cm}, L_{i}=34 \mathrm{~cm}, H_{o}=38.5 \mathrm{~cm}$, and $\theta=15^{\circ}$, at four different times from the opening of the sluice gate. A movie of the same experiment and a compilation of experimental movies from different camera viewpoints are also available in the Supporting Information.

\section{Gas-fluidized granular flows entering water}

At the initial time $t=0$, the initial column of grains is released, collapses and forms a gas-fluidized granular flow on the subaerial inclined plane until reaching water. The impact between the granular flow and the water body generates (i) an initial granular jet corresponding to grains ejected above the water surface, (ii) a leading and largest wave, and (iii) a turbulent mixing zone from which a particle-driven gravity current is spontaneously formed (Figure 3). These observations are direct consequences of the presence of a water body, which have already been observed for fine particle-fluid mixtures entering water (Mcleod et al., 1999; Freundt, 2003; Allen et al., 2012; Bougouin et al., 2020). By contrast, both the granular jet and the gravity current have never been reported in the literature for coarse granular materials [i.e., $d>\mathcal{O}\left(10^{-3}\right) \mathrm{m}$ ] under similar flow conditions (e.g., Fritz et al., 2003a; Heller et al., 2008; Viroulet et al., 2014; Zitti et al., 2016; Miller et al., 2017). It suggests therefore that both the granular jet and the particle-driven gravity current are mainly controlled by the grain-fluid interaction. In fact, the flow dynamics of particle-driven gravity currents along the bottom plane looks more like that of homogeneous gravity currents penetrating a two-fluid layer (Monaghan et al., 1999; Legros \& Druitt, 2000; Monaghan, 2007; Wells \& Wettlaufer, 2007; Cortés et al., 2014). In this configuration, a splitting of the homogeneous gravity current can even be obtained, which could be related to the formation of the granular jet above the water surface and of the particle-driven gravity current underwater. However, some caution has to be exercised here because the splitting of homogeneous gravity currents was attributed to lighter fluid incorporated into the current by turbulent entrainment (Wells \& Wettlaufer, 2007; 


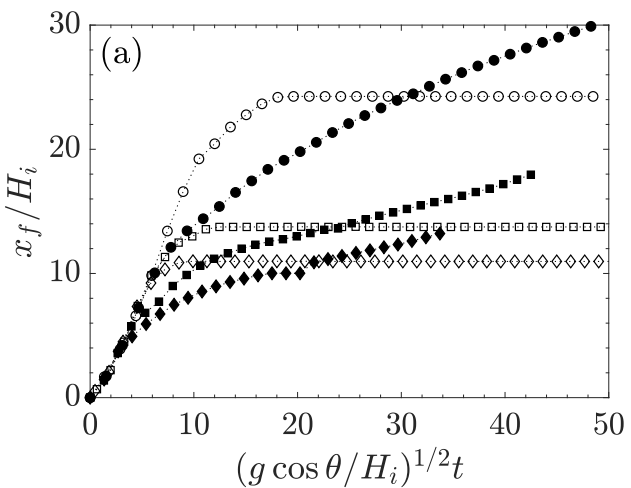
agating in air.

Cortés et al., 2014), which is not expected to occur for gas-fluidized granular flows prop-

\subsection{Comparison with gas-fluidized granular flows in air}

In this section, we highlight the effect of a water body on the granular dynamics and the associated deposits by comparison of gas-fluidized granular flows propagating only in air and entering water, under the same initial conditions.

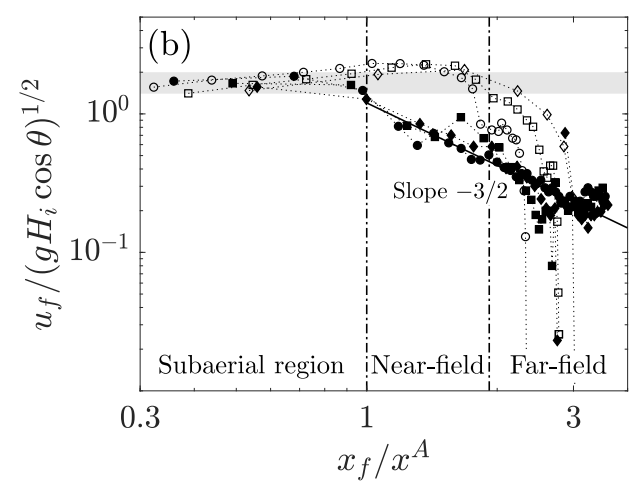

Figure 4. (a) Front position $x_{f} / H_{i}$ as a function of normalized time $\left(g \cos \theta / H_{i}\right)^{1 / 2} t$ for gasfluidized granular flows propagating in air (opened symbols) and entering water (closed symbols), with $H_{i}=10 \mathrm{~cm}$ (diamonds), $H_{i}=22 \mathrm{~cm}$ (squares) and $H_{i}=30 \mathrm{~cm}$ (circles). The other initial parameters are set to $L_{i}=34 \mathrm{~cm}, \theta=15^{\circ}$, and $H_{o}=26.6 \mathrm{~cm}$ (in the presence of water). (b) Front-velocity $u_{f} /\left(g H_{i} \cos \theta\right)^{1 / 2}$ as a function of the front position $x_{f} / x^{A}$, where $x^{A}$ is the streamwise coordinate of the shoreline. The gray area corresponds to $u_{f} /\left(g H_{i} \cos \theta\right)^{1 / 2}=[1.4: 2]$; the solid line is a slope $-3 / 2$; and the dotted-dashed lines delimit the subaerial, near- and farfield regions.

One of the relevant macroscopic analyses to compare the dynamics of granular flows is the tracking of the front position $x_{f}$ and the front-velocity $u_{f}$ with time and position (Figure 4). The presence of a water body significantly affects the temporal evolution of the flow front beyond the initial height $H_{i}$, the latter being already reported for water dam-break flows (e.g., Ritter, 1892; Laubert \& Hager, 1998; Ancey et al., 2008) and subaerial granular flows (e.g., Roche et al., 2008; Mangeney et al., 2010; Farin et al., 2014; Bougouin et al., 2020). At early times, all curves collapse together corresponding to the propagation of granular flows down the subaerial inclined plane. During this stage, the flow front slightly accelerates along the plane, as predicted by the theory for a frictionless fluid flow down an inclined plane (Ancey et al., 2008). We recall that the acceleration phase of channeled granular flows is expected to end when the gravity is balanced by sidewall friction (Brodu et al., 2015). For the sake of simplicity, the averaged front velocity can also be defined in the range $u_{f} /\left(g H_{i} \cos \theta\right)^{1 / 2}=[1.4: 2]$ [gray area, in Figure 4(b)], in agreement with values found in the case of dam-break flows on a horizontal plane (Dressler, 1954; Jánosi et al., 2004; Leal et al., 2006; Roche et al., 2008; Bonometti et al., 2008; Bougouin et al., 2017). During the second phase, gas-fluidized granular flows either enter water and then propagate in the form of subaqueous particle-driven gravity currents, or they continue to flow down the subaerial inclined plane without the sustained gas flow from the bottom. The main consequence of the water body is to slow down the spreading of the granular material. A gross estimate of the normalized front velocity with the normalized front position gives $u_{f} /\left(g H_{i} \cos \theta\right)^{1 / 2} \propto\left(x_{f} / x^{A}\right)^{-3 / 2}$ [solid line, 
in Figure 4(b)]. However, the flow dynamics of the currents will be more fully investigated in Sec. 5. Finally, the gas-fluidized granular flows in air stop rapidly on the horizontal bottom, while the gravity currents continue slowly to propagate underwater [Farfield region, in Figure 4(b)].

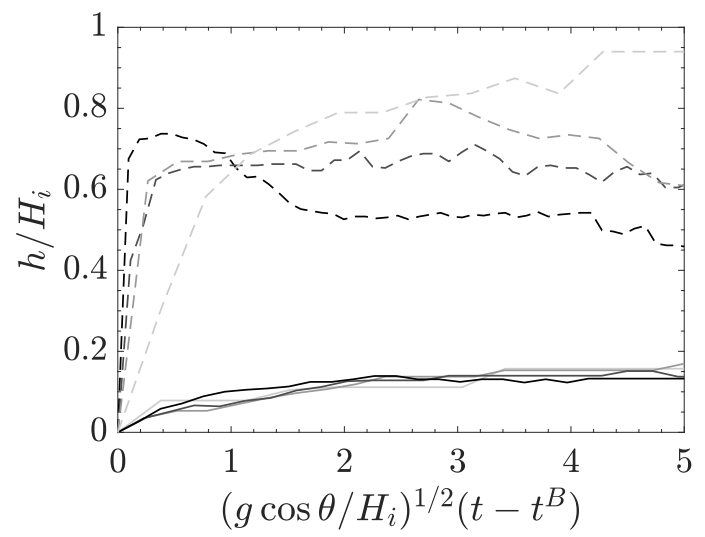

Figure 5. Temporal evolution of the flow height $h / H_{i}$ at the slope break $x-x^{B}=0$, for gasfluidized granular flows propagating in air (-) and entering water (- - ), with $H_{i}=10,22,30$ and $42 \mathrm{~cm}$ (from light to dark gray). The other initial parameters are set to $L_{i}=34 \mathrm{~cm}, \theta=15^{\circ}$, and $H_{o}=26.6 \mathrm{~cm}$ (in the presence of water).

The morphology of the granular flow can also be investigated here, because it is particularly modified by the presence of the water body (Figure 5). More specifically, the major effect of water is to generate thick and dilute particle-driven gravity currents underwater compared to dense and thin gas-fluidized granular flows in air. Moreover, the inertial dimensionless form used here allows the collapse of the height profile of gasfluidized granular flows obtained for different $H_{i}$, which does not hold true for subaqueous particle-driven gravity currents.

Finally, at sufficiently long times (i.e., from a few seconds to tens of seconds), the granular material stops forming a final deposit along the bottom surface (Figure 6). Again, the morphology of the granular deposit strongly differs for gas-fluidized granular flows propagating in air and those entering water. The presence of the water body leads to a thick and voluminous granular mass along the inclined plane probably due to a dense granular flow, while a thin layer of grains, initially suspended in the gravity current, is deposited on the horizontal bottom. By contrast, the subaerial granular flows form only a massive deposit at the end of the inclined plane. The inset of Figure 6 shows that the presence of water reduces significantly the runout of granular flows, as already reported for coarse grains falling into water (Mazzanti \& De Blasio, 2011; Viroulet et al., 2014; Miller et al., 2017). The runout is defined here as $h\left(x-x^{B}=R_{f}\right)=H_{i} / 10$ to be free of the thin and very elongated granular layer deposited by the current. Overall, the presence of the water body therefore plays a dissipative role by slowing and reducing the spreading of the granular material, even if a low amount of grains are still transported by the turbulent fluid far away.

\subsection{Discussion of results}

Our laboratory experiments on fine-grained granular flows entering a water body have revealed the following results. Overall, the presence of water promoted the formation of a granular jet, corresponding to grains ejected above the water surface and then 


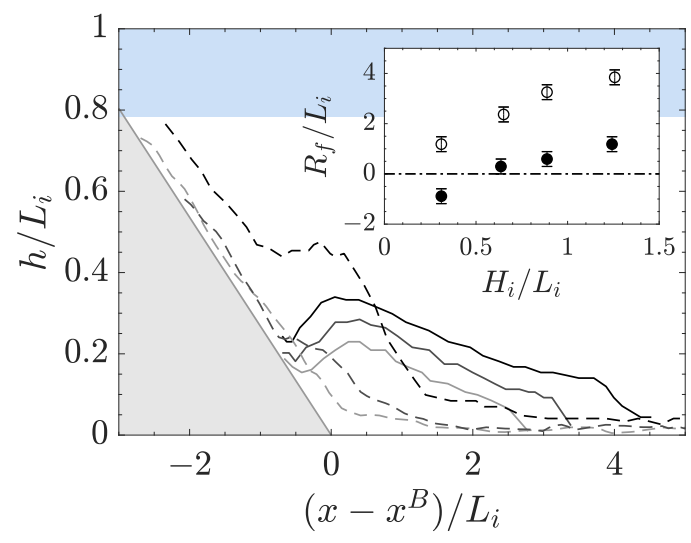

Figure 6. Morphology of granular deposits along the bottom surface, for gas-fluidized granular flows propagating in air (-, opened circles) and entering water (- - , closed circles), with $H_{i}=22,30$ and $42 \mathrm{~cm}$ (from light to dark gray). The other initial parameters are set to $L_{i}=34 \mathrm{~cm}, \theta=15^{\circ}$, and $H_{o}=26.6 \mathrm{~cm}$ (in the presence of water). Inset: Runout $R_{f} / L_{i}$, defined as $h\left(x-x^{B}=R_{f}\right)=H_{i} / 10$, as a function of the aspect ratio $a=H_{i} / L_{i}$ of the initial column.

falling onto it, and a particle-driven gravity current underwater. Moreover, hydrodynamics forces mainly played a dissipative role by slowing and reducing the spreading of the granular mass underwater, even if a low amount of grains were still transported by the turbulent fluid as a gravity current far away. These observations highlight the complexity of granular flows impacting water, with in particular, a splitting of granular masses. These results are now discussed to help the interpretation of some submarine deposits in the natural environment.

In the field, both the morphology and the internal structure of deposited material represent a suitable marker of the dynamics of granular flows. In the case of fine-grained geophysical flows entering water, it is expected from our experiments to obtain distinct submarine deposits, recording successively gravity currents, dense basal flows, and granular jets. The 1995-2010 eruption of Soufrière Hills volcano represents an invaluable case study of pyroclastic flows entering the sea with volcanic activity having been intensively documented (e.g., Young et al., 1998; Trofimovs et al., 2006, 2008; Le Friant et al., 2009, 2010; Trofimovs et al., 2012; Wadge et al., 2014, among others). A large part of volcaniclastic materials was transported into the sea, and associated submarine deposits have been particularly well described through bathymetric survey data and core samples. Overall, massive coarse-grained deposits were observed close to the slope break, which was interpreted as the sign of dense granular flows propagating slowly underwater (Le Friant et al., 2009, 2010; Trofimovs et al., 2012). A grain-size sorting process also promoted the formation of dilute turbidity currents composed of fine materials, which deposited as thin and elongated masses far away from the shoreline (Trofimovs et al., 2006, 2008, 2012). Our experimental observations of submarine gravity currents and deposit morphologies are consistent with those reported from the field. Additionally, they highlight that grain-size sorting processes are not needed to form both proximal massive deposits and distal turbidites. Finally, deposits of granular jets have never been mentioned in the literature, suggested that they were probably hardly recognized. 
(b)

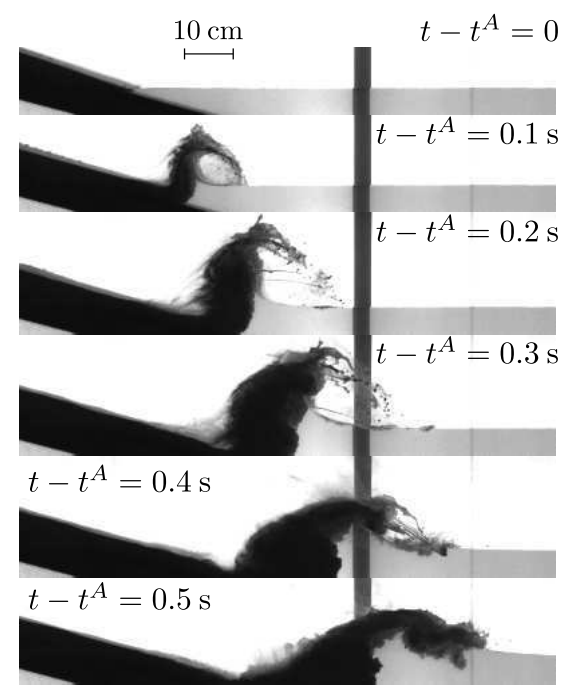

Figure 7. (a) Sketch of a gas-fluidized granular flow before (upper) and after (bottom) the impact with water. The trajectory of the granular jet is characterized by the crest position $\left(X_{c}\right.$, $Y_{c}$ ) reaching a maximum height at the position $\left(X_{c}^{m}, Y_{c}^{m}\right)$ and the time $T^{m}$, and described by ballistic motion theory considering an initial velocity $u_{i}$ and an initial angle $\alpha$. (b) Snapshots of the typical evolution of a granular jet for $u_{f}=3.0 \mathrm{~m} \cdot \mathrm{s}^{-1}$ and $\theta=15^{\circ}$, at different times from the impact.

\section{Spatio-temporal evolution of the granular jet}

The entrance of a gas-fluidized granular flow into a water body generates first a granular jet above the water surface, before falling onto it. Here, we propose to describe the spatio-temporal evolution of the position of the jet crest $\left(X_{c}, Y_{c}\right)$ considering a ballistic trajectory. A sketch of this issue is shown in Figure 7(a), with the flow parameters before entering water (upper) and the granular jet after the impact (bottom). It can already be anticipated that both the initial length $L_{i}$, which only controls the volume of the granular flow, and the water depth $H_{o}$ could be disregarded here, as the granuar jet is rapidly generated near the shoreline. The control parameters for this problem therefore the slope angle $\theta$ of the inclined plane and the front velocity $u_{f}$, the laton controlled by the initial height $H_{i}$ of the column and the slope angle $\theta$. Figat different times from the impact. Note that the granular jet could also contain some water, but the proportion is expected to be low compared to those of grains and the ambient air.

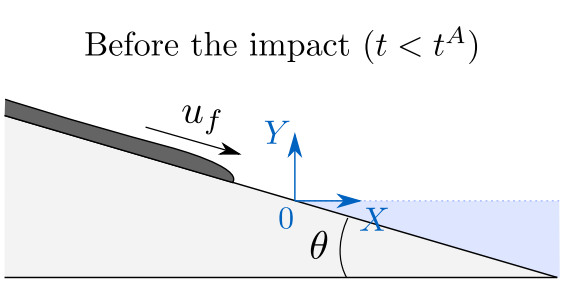

After the impact $\left(t>t^{A}\right)$

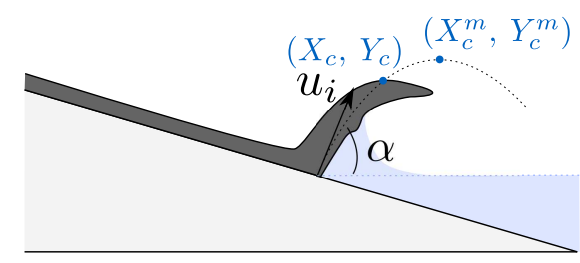

\subsection{Frictionless ballistic motion theory}

For the purpose of describing the trajectory of the granular jet crest, let us first consider a single grain ejected with an initial velocity $u_{i}$ and an initial angle $\alpha$ (with respect to the horizontal plane), i.e. $\left(X_{c}, Y_{c}\right)=(0,0)$ and $t-t^{A}=0$ with $t^{A}$ the time at the impact [see Figure 7(a)]. To first order, the drag force of the ambient air on the grain motion can be neglected. Hence, the single grain is only subject to its own weight and momentum conservation reduces to $\left(d^{2} X_{c} / d t^{2}, d^{2} Y_{c} / d t^{2}\right)=(0,-g)$ in the hori- 
zontal and vertical directions, respectively. Then one can simply obtain the temporal evolution of the horizontal and vertical positions of the grain as

$$
\begin{aligned}
X_{c} & =u_{i} \cos \alpha\left(t-t^{A}\right), \\
Y_{c} & =-\frac{g}{2}\left(t-t^{A}\right)^{2}+u_{i} \sin \alpha\left(t-t^{A}\right) .
\end{aligned}
$$

Additionally, the spatial evolution can also be expressed by combining equations (1) and (2), which leads to

$$
Y_{c}=-\frac{g}{2 u_{i}^{2} \cos ^{2} \alpha} X_{c}^{2}+\tan \alpha X_{c} .
$$

It can also be useful to predict the position $\left(X_{c}^{m}, Y_{c}^{m}\right)$ and the time $T^{m}$ at which the maximum height is reached as discussed later in Sec. 4.3. This is obtained when $d Y_{c} / d t=$ $d Y_{c} / d X_{j}=0$, at $t=T^{m}$ and $X_{c}=X_{c}^{m}$. Using equations (1), (2) and (3), we obtain

$$
X_{c}^{m}=\frac{\cos \alpha \sin \alpha}{g} u_{i}^{2}, \quad Y_{c}^{m}=\frac{\sin ^{2} \alpha}{2 g} u_{i}{ }^{2}, \quad T^{m}=\frac{\sin \alpha}{g} u_{i} .
$$

It should be noted that each quantity depends only on the initial conditions of the ballistic trajectory, i.e. the initial velocity $u_{i}$ and the initial angle $\alpha$. Now, we assume that the grain motion of the jet crest can be related to that of a single grain with a ballistic trajectory, which can be anticipated to be a crude assumption in view of dense granular flows impacting the water body. In fact, this suggests that grain-grain interaction can be neglected, at least in the upper region of the granular jet. In the following, it will be shown that this model captures most of the physical mechanisms, giving a fairly good description of the spatio-temporal evolution of the granular jet.

\subsection{Application to the experiments}

The validity of the predictive model is now assessed from experimental data. Figure 8 shows a fairly good collapse of the spatio-temporal evolution of the granular jet crest, using $\left(X_{c}^{m}, Y_{c}^{m}\right)$ and $T^{m}$ as length and time scales. The duration of the jet is $(t-$ $\left.t^{A}\right) / T^{m} \sim 1.5$ here, from which the jet falls down the generated leading wave. Moreover, $X_{c} / X_{c}^{m}$ and $Y_{c} / Y_{c}^{m}$ have a quasi-linear and a $2-$ polynomial trend with the time $\left(t-t^{A}\right) / T^{m}$ [solid lines, in Figs. 8(a)-(b)], which is consistent with the form of the theoretical predictions given by equations (1) and (2), respectively. Similar conclusions can also be drawn from the spatial evolution of the granular jet [Figure 8(c)] in comparison with equation (3). This supports the idea that the trajectory of the jet crest could be simply described from a frictionless ballistic trajectory of grains. Finally, the insets of Figure 8 show the spatio-temporal evolution of the jet crest generated by dense liquid flows impacting a water body (salt water into fresh water, here). In this case, the jet corresponds to a volume of dense liquid ejected above the water surface. The dynamics of liquid jets is equivalent to that of granular jets, as shown by the collapse of the experimental data and the solid lines. In the present configuration, the jet dynamics is therefore mainly dependent on the flow conditions (e.g., flow velocity, slope angle), regardless of the rheology of the flowing material (e.g., Newtonian fluid, granular material).

In order to describe the spatio-temporal evolution of the granular jet, the initial parameters $\left(u_{i}, \alpha\right)$ of the model have to be quantified from the flow conditions. The temporal evolution of the horizontal and vertical positions of the granular jet crest, i.e. $X_{c}(t)$ and $Y_{c}(t)$, are fitted by equations (1) and (2), respectively, for which $u_{i}$ and $\alpha$ can be 

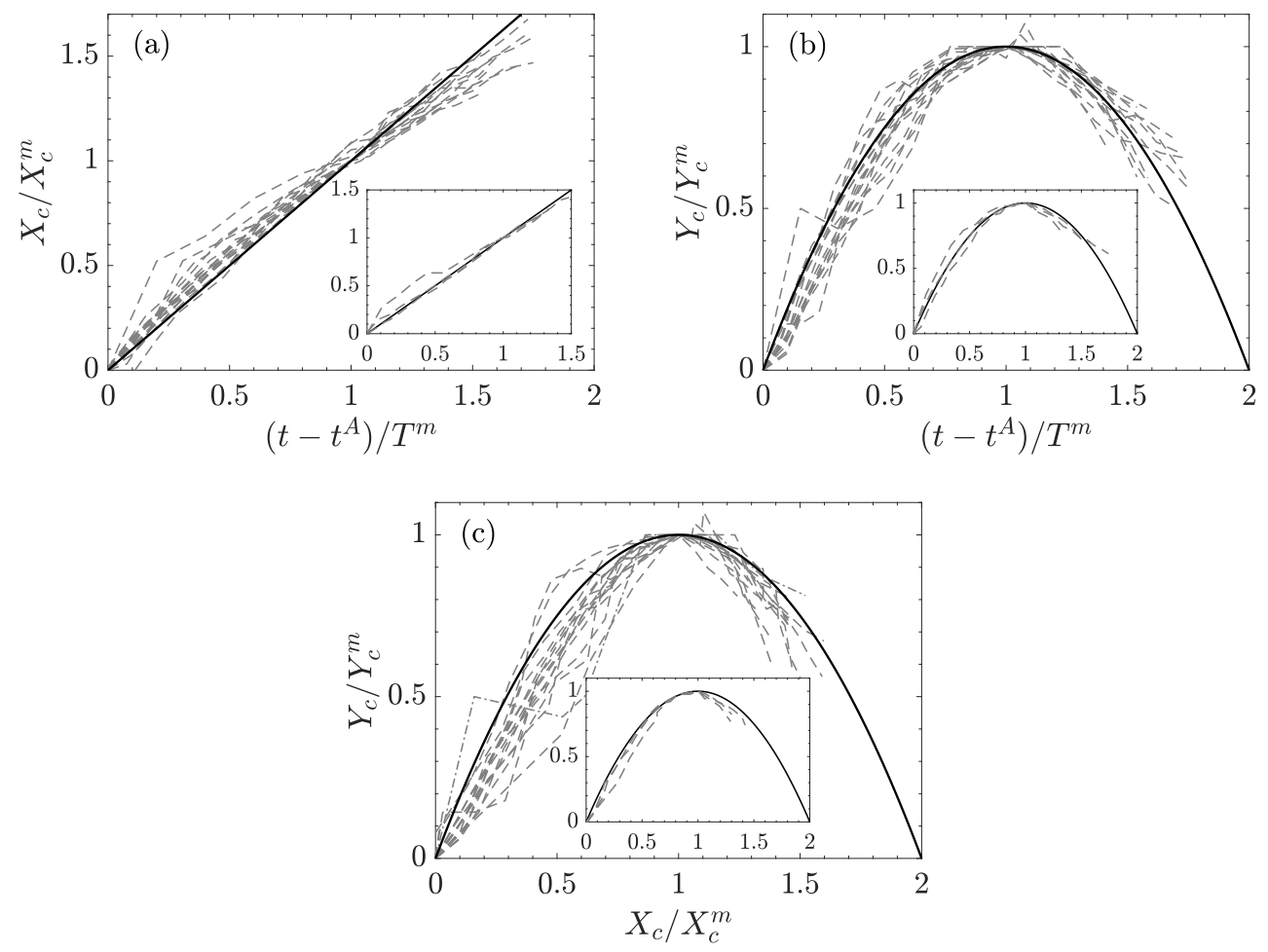

Figure 8. Evolution of (a) the horizontal position $X_{c} / X_{c}^{m}$ and (b)-(c) the vertical position $Y_{c} / Y_{c}^{m}$ of the jet crest generated by gas-fluidized granular flows (insets: dense liquid flows) impacting a water body, as a function of (a)-(b) the time $\left(t-t^{A}\right) / T^{m}$ and (c) the horizontal position $X_{c} / X_{c}^{m}$, where $\left(X_{c}^{m}, Y_{c}^{m}\right)$ and $T^{m}$ are the position and the time at which the maximum height of the jet crest is reached. The solid lines correspond to (a) $X_{c} / X_{c}^{m}=\left(t-t^{A}\right) / T^{m}$, (b) $Y_{c} / Y_{c}^{m}=-\left[\left(t-t^{A}\right) / T^{m}\right]^{2}+2\left(t-t^{A}\right) / T^{m}$, and (c) $Y_{c} / Y_{c}^{m}=-\left(X_{c} / X_{c}^{m}\right)^{2}+2 X_{c} / X_{c}^{m}$, respectively.
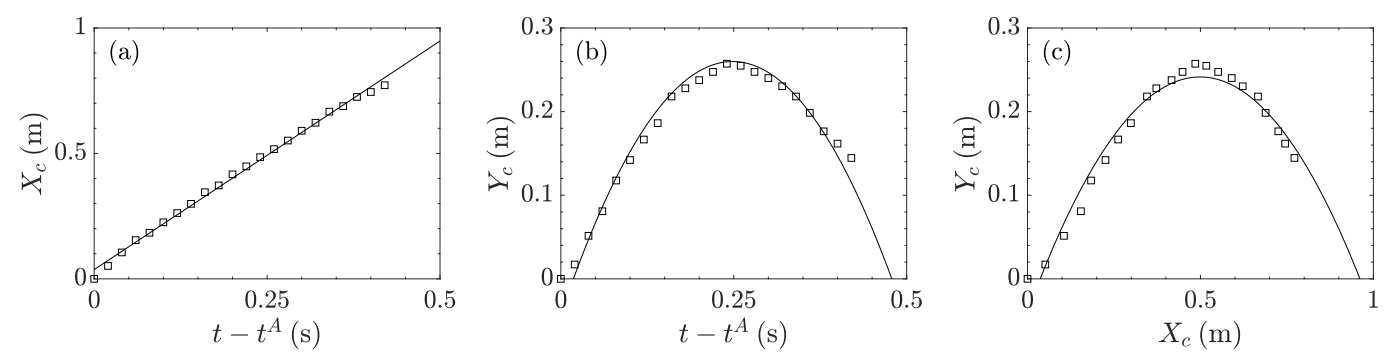

Figure 9. Spatio-temporal evolution of the granular jet crest, with $u_{f}=3.0 \mathrm{~m} \cdot \mathrm{s}^{-1}$ and $\theta=15^{\circ}$. Squares and solid lines correspond to the experimental data and the theoretical predictions [equations (1), (2) and (3)] with (a)-(b) $u_{i} \sim 3.0 \mathrm{~m} . \mathrm{s}^{-1}$ and $\alpha \sim 53^{\circ}$, and (c) $u_{i} \sim 3.1 \mathrm{~m} . \mathrm{s}^{-1}$ and $\alpha \sim 48^{\circ}$, respectively. To overcome the problem of time and space offsets, the fitted relations are not set to $\left(X_{c}, Y_{c}\right)=(0,0)$, at $t-t^{A}=0$.

adjusted. To overcome the problem of time and space offsets, the fitted relations are not set to $\left(X_{c}, Y_{c}\right)=(0,0)$, at $t-t^{A}=0$. A similar method is also realized with the spatial evolution of the granular jet crest, i.e. $Y_{c}\left(X_{c}\right)$, using equation (3). Figure 9 shows 
an example of the good agreement between the experimental data and the fitted theoretical predictions. Here, the initial parameters of the model are equal to (a) and (b) $u_{i} \sim$ $3.0 \mathrm{~m} . \mathrm{s}^{-1}$ and $\alpha \sim 53^{\circ}$ and (c) $u_{i} \sim 3.1 \mathrm{~m} . \mathrm{s}^{-1}$, and $\alpha \sim 48^{\circ}$, respectively. As two different values of $u_{i}$ and $\alpha$ are obtained by the extracted method, the values and errorbars used in the following correspond to the averaged value and the standard deviation, respectively.
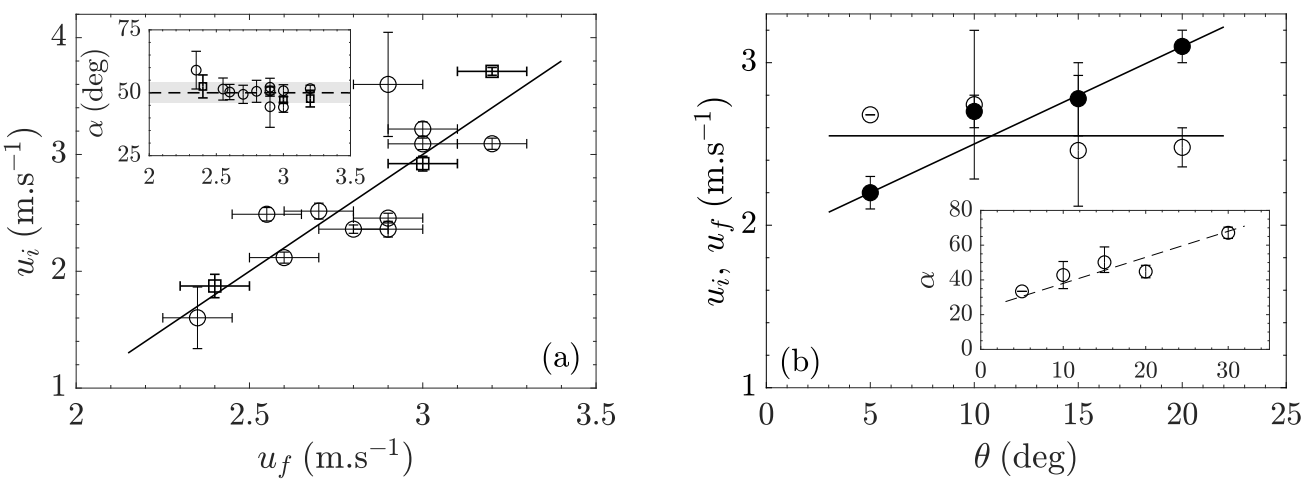

Figure 10. (a) Initial velocity $u_{i}$ (inset: initial angle $\alpha$ ) as a function of the front-velocity $u_{f}$ of gas-fluidized granular flows (circles) and dense liquid flows (squares) at the impact with water, with $\theta=15^{\circ}$. The solid line is $u_{i}=2 u_{f}-3$, and the dashed line and gray area correspond to $\alpha=50 \pm 4^{\circ}$. (b) Initial velocity $u_{i}$ (opened circles) and front-velocity $u_{f}$ (closed circles) as a function of the slope angle $\theta$ of the inclined plane, with $H_{i} \sim 22 \mathrm{~cm}$. The solid lines are $u_{i}=2.55 \mathrm{~m} . \mathrm{s}^{-1}$ and $u_{f}=0.06 \theta+1.9$, respectively. Inset: $\alpha$ as a function of $\theta$, with $\alpha=1.5 \theta+23$ (dashed line).

The estimated parameters of the model, i.e. the initial velocity $u_{i}$ and the initial angle $\alpha$, are plotted as a function of the relevant parameters of the problem, i.e. the flowfront velocity $u_{f}$ before entering water and the slope angle $\theta$ of the inclined plane [Figure 10]. As expected, the initial velocity $u_{i}$ is related to the flow-front velocity $u_{f}$ being the relevant velocity scale of the problem [Figure 10(a)]. By constrast, the initial angle $\alpha$ is not affected by $u_{f}$, which is found equal to $\alpha=50 \pm 4^{\circ}$, for a given slope angle of $\theta=15^{\circ}$ [dashed line and gray area, in the inset of Figure 10(a)]. Additionally, Figure 10(b) shows the effect of $\theta$ on the initial parameters $\left(u_{i}, \alpha\right)$ of the model. Surprisingly, $u_{i}$ remains broadly constant, while $u_{f}$ increases for increasing $\theta$ (opened vs. closed symbols). Here, the variation of $u_{f}$ is only attributed to the slope angle $\theta$, as the initial height of the column is kept constant. This observation seems to be inconsistent with the conclusions drawn from Figure 10(a), for which $u_{i}$ and $u_{f}$ increase together. In fact, this could suggest that the driving effect of $u_{f}$ on the initial velocity $u_{i}$ is here counterbalanced by a dissipative effect of $\theta$. In the inset of Figure 10(b), it is shown that $\alpha$ increases with $\theta$. This means that grains substain a change of their direction more abrupt at larger $\theta$ (i.e., from $\alpha+\theta \sim 40^{\circ}$ to $\alpha+\theta \sim 100^{\circ}$ with $\theta=[5: 30]^{\circ}$ ) which could strongly promote dissipation in the system.

\subsection{Discussion of results}

Experiments showed that the spatio-temporal evolution of the position of the granular jet crest above the water surface can be well described using the theoretical prediction of a frictionless ballistic motion. This simple model requires only two parameters, i.e. the initial velocity $u_{i}$ and the initial angle $\alpha$ of the ballistic trajectory, which are di- 
rectly related to the flow-front velocity $u_{f}$ and the slope angle $\theta$ of the inclined plane. In the following, the predictive model is applied to a recent natural event to assess its accuracy for geophysical applications.

Stromboli volcano (Italy) has persistent explosive activity with several hundreds of moderate-intensity events per day, and some notable paroxysmal phases. The 03 July and 28 August 2019 paroxysmal explosions produced eruptive columns of more than 5 $\mathrm{km}$ height, whose collapse generated pyroclastic density currents travelling rapidly along the northern flank of the volcano and entering the Mediterranean Sea (Giudicepietro et al., 2020). Recorded images of the impact of pyroclastic density currents into water showed the generation of volcaniclastic jets above the sea level, from which the maximum height of a granular jet crest could be approximately estimated as $Y_{c}^{m} \sim 200 \mathrm{~m}$. In the present case, equation (4) can therefore be reversed to provide an estimate of the impact velocity of the pyroclastic flow, knowing that the values of both $u_{f} \sim 70 \mathrm{~m} . \mathrm{s}^{-1}$ and $\alpha \sim$ $50^{\circ}$ are also extracted from videos of LBZ webcam of Laboratorio Geofisica Sperimentale (lgs.geo.unifi.it). The predictive model gives an impact velocity of $u_{i} \sim 68 \mathrm{~m} . \mathrm{s}^{-1}$, with $Y_{c}^{m}=200 \mathrm{~m}$ and $\alpha=50^{\circ}$, which is in excellent agreement with the direct measurement of the flow velocity $u_{f} \sim 70 \mathrm{~m} . \mathrm{s}^{-1}$. It should be mentioned, however, that recorded images suggest a lower streamwise position $X_{c}^{m}$ of the maximum crest height compared to the vertical position $Y_{c}^{m}$, unlike the prediction of the model, but the estimate of $X_{c}^{m}$ is poorly constrained. In any case, this result suggests that the theoretical prediction of a frictionless balistic motion could be successfully used for granular jets generated by fine-grained geophysical flows entering water to provide an estimate of their impact velocity, which is unvaluable for the hazard assessment of tsunami generation.

\section{Flow dynamics of the particle-driven gravity current}

In this section, we focus on the propagation of particle-driven gravity currents along the inclined plane and the horizontal bottom underwater, referred to as the near- and far-field regions, respectively (Figure 11). The current is characterized by the height profile $h(x, t)$, the front position $x_{f}$, and the bulk volume concentration of particles $\phi$ as a function of the flow rate per unit width $q$ and the volume per unit width $v$ of the granular flow, the slope angle $\theta$ and the water depth $H_{o}$. It should be remembered that the gas-fluidized granular flow enters the water body at $x_{f}=x^{A}$ and $t=t^{A}$, and then the current reaches the slope break at $x_{f}=x^{B}$ and $t=t^{B}$.

\subsection{Near-field region: gravity current over an inclined plane}

The first stage of the flow dynamics of particle-driven gravity currents underwater corresponds to the flow propagation along the inclined plane in the near-field region. It can already be anticipated that the water depth $H_{o}$ could be disregarded here, being sufficiently far from the inclined plane. This is supported by results (Figure S1, in the Supporting Information) and the present configuration is therefore reduced to three control parameters here, i.e. $q, v$ and $\theta$.

Figure 12 shows the temporal evolution of the front position $x_{f}-x^{A}$ varying (a) the flow rate per unit width $q$, (b) the volume per unit width $v$, and (c) the slope angle $\theta$ of the inclined plane. In the first two cases, other control parameters are strictly kept constant while, in the latter case, the flow-front velocity $u_{f}$, and therefore the flow rate $q$, varies with the slope angle $\theta$ of the inclined plane. First, it can be clearly observed that both $q$ and $v$ affect the propagation of the front position, while $\theta$ can be disregarded here. More specifically, $q$ modifies the whole propagation of the current, with in particular, a front propagation slower at lower $q$ than at larger $q$ [from light to dark gray, in Figure 12(a)]. By contrast, the influence of $v$ is only clear for $t \gtrsim 0.5 \mathrm{~s}$, from which all data deviate from the master curve. In this case, the flow front of currents propagates slower at lower $v$ than at larger $v$ [from light to dark gray, in Figure 12(b)]. This tran- 


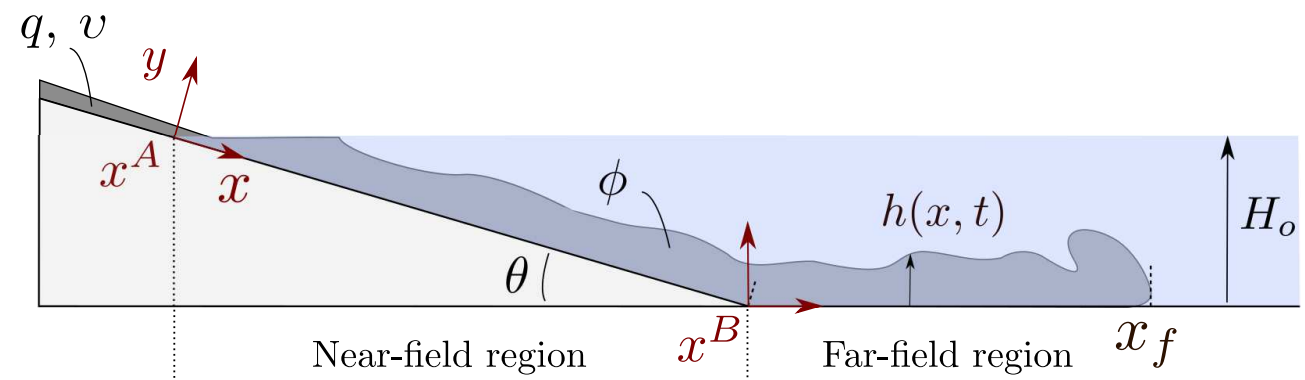

Figure 11. Sketch of the propagation of a particle-driven gravity current along a bottom plane with its macroscopic quantities [height profile $h(x, t)$, front position $x_{f}$ and bulk volume concentration of particles $\phi$ ], and the control parameters (flow rate per unit width $q$ and volume per unit width $v$ of the granular flow, slope angle $\theta$, and water depth $H_{o}$ ) of the problem. The streamwise coordinates $x^{A}$ and $x^{B}$ indicate the transition from the $1 \mathrm{~m}$-subaerial ramp to the immersed ramp, and the end of the inclined plane that connects to the horizontal bottom, respectively. The zones containing the immersed inclined plane and the horizontal bottom are referred to as the near- and far-field regions, respectively.

sient behavior can probably be attributed to the end of the granular inflow. Finally, the influence of $q$ and $v$ is hardly observed from the height profile of currents (insets of Figure 12), which supports the idea that the front position evolution is more relevant to quantify the flow dynamics of currents in the near-field region.

These results show that, as long as the entire granular volume has not yet entered the fluid layer, the flow rate per unit width $q$ mostly controls the front dynamics of the gravity current beneath the free-surface. This observation can be related to a homogeneous gravity current produced by a constant flux over an inclined plane, for which the front position scales as $x_{f} \propto\left(g^{\prime} Q\right)^{1 / 3} t$, with $g^{\prime}=2 g\left(\rho-\rho_{f}\right) /\left(\rho+\rho_{f}\right)$ the reduced gravity, $\rho$ and $\rho_{f}$ the densities of the current and of the surrounding fluid, respectively, and $Q$ the flow rate per unit width (Britter \& Linden, 1980). It is difficult to consider this scaling in the present configuration, given that the flow rate per unit width $Q$ beneath the free-surface and the bulk density $\rho$ of currents are unknown. However, we make the somewhat crude assumptions that the flow rate per unit width $q$ at the impact is related to the flow rate per unit width $Q$ beneath the free-surface, and that the bulk volume concentration of particles $\phi$, and therefore the reduced gravity $g^{\prime}$, do not vary significantly in the range of parameters considered here. The latter issue will be more fully discussed in Sec. 5.2. Under these assumptions, the front position $x_{f}-x^{A}$ is plotted as a function of $(g q)^{1 / 3}\left(t-t^{A}\right)$ in Figure 13, for the same set of experiments shown in Figure 12(a). Surprisingly, a very good collapse of the experimental data is obtained for different flow rates per unit width $q$, which supports the use of this scaling. More specifically, it is not necessary to consider the reduced gravity $g^{\prime}$, which means that the particle concentration $\phi$ of currents is fairly constant here. The inset of Figure 13 shows that all experimental data are included in a low interval delimited by two scaling laws, i.e. $x_{f}-x^{A}=\lambda(g q)^{1 / 3}\left(t-t^{A}\right)$ with $\lambda=1.3$ and 2 (gray area). At large times, the front position deviates from the linear trend, which is probably caused by the end of the granular inflow. The dynamics could tend towards the power-law evolution $x_{f} \propto t^{2 / 3}$ of a finite volume released over an inclined plane (Dai, 2013, 2014), represented by the dashed line in the inset of Figure 13. However, the inclined plane is not long enough in this study to fully support this interpretation. 
(a)

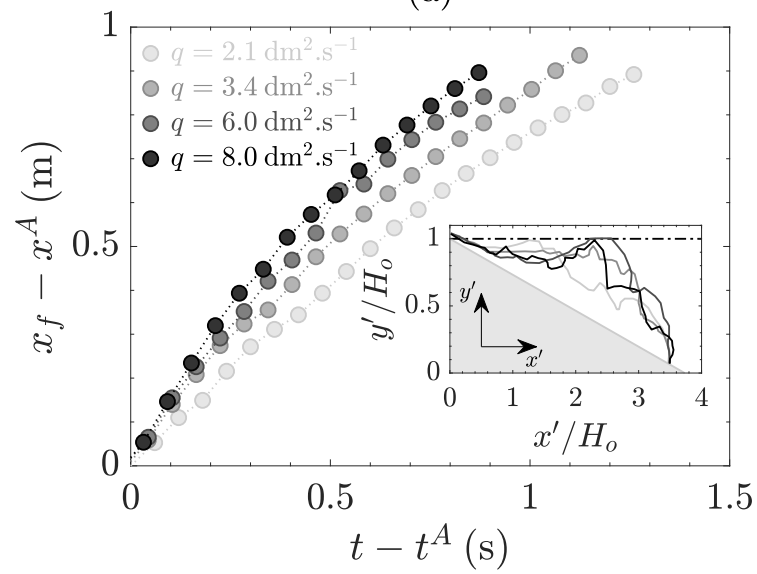

(b)

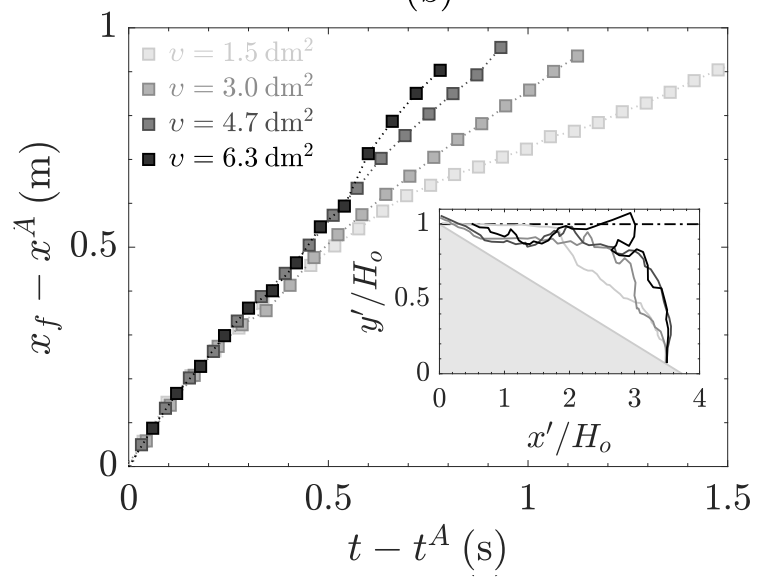

(c)

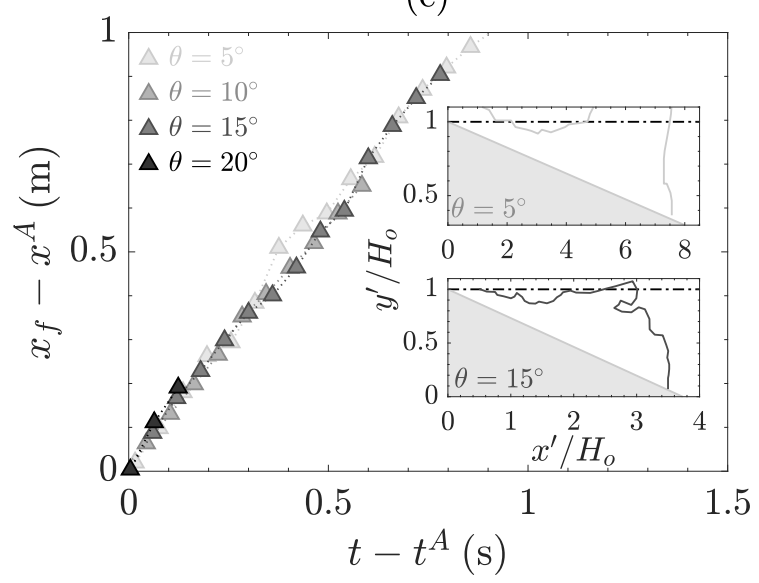

Figure 12. Near-field region: temporal evolution of the front position $x_{f}-x^{A}$ of the particledriven gravity currents by varying (a) the flow rate per unit width $q\left(v \sim 3.1 \mathrm{dm}^{2}, \theta=15^{\circ}\right)$, (b) the volume per unit width $v\left(q \sim 3.3 \mathrm{dm}^{2} . \mathrm{s}^{-1}, \theta=15^{\circ}\right)$, and $(\mathrm{c})$ the slope angle $\theta(q=[2.6: 4.3]$ $\left.\mathrm{dm}^{2} \cdot \mathrm{s}^{-1}, v \sim 6.2 \mathrm{dm}^{2}\right)$. Insets: Height profile of currents along the inclined plane, at $x_{f}-x^{A} \sim$ $1 \mathrm{~m}$. 


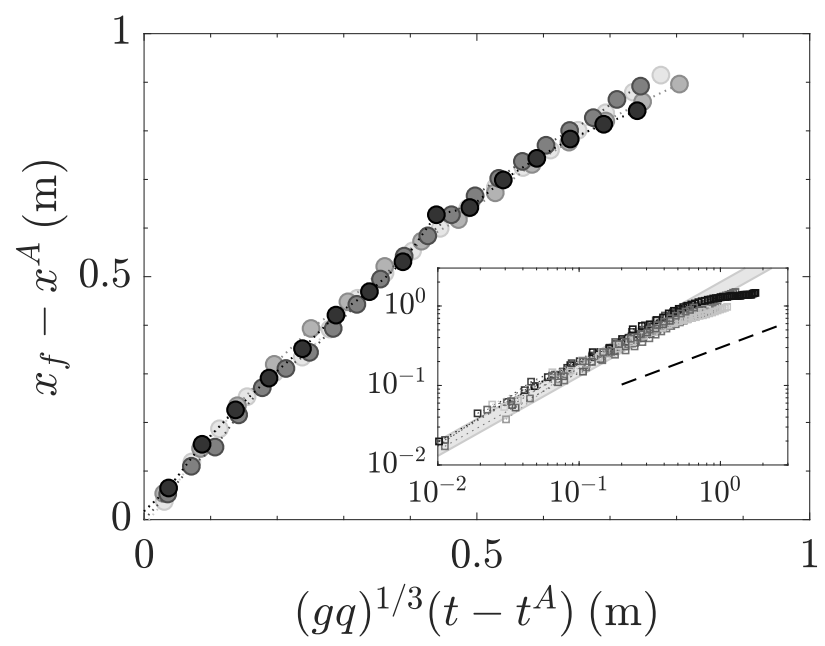

Figure 13. Near-field region: front position $x_{f}-x^{A}$ of the particle-driven gravity currents as a function of $(g q)^{1 / 3}\left(t-t^{A}\right)$ [based on Britter and Linden (1980)], for the same set of experiments shown in Figure 12(a) (inset: for the whole set of experiments, in a log-log representation). Gray area: $x_{f}-x^{A}=\lambda(g q)^{1 / 3}\left(t-t^{A}\right)$ delimited by $\lambda=1.3$ and $2 ;(---) x_{f}-x^{A} \propto\left(t-t^{A}\right)^{2 / 3}$.

\subsection{Far-field region: gravity current over a horizontal bottom}

The front of the particle-driven gravity current reaches the slope break, at $x_{f}-$ $x^{B}=0$ and $t-t^{B}=0$. Then, it propagates on the horizontal bottom until it reaches the end of the channel, referred to as the far-field region. Figure 14 shows $x_{f}-x^{B}$ as a function of $t-t^{B}$ for different flow rates per unit width $q$ and volumes per unit width $v$ of the granular flow, while the water depth and the slope angle are set to $H_{o} \sim 26.5$ $\mathrm{cm}$ and $\theta=15^{\circ}$, respectively. Additionally, the front dynamics of homogeneous gravity currents generated by the impact of dense liquid flows into water is shown, for different $q$ and $v$ (blue circles, in inset of Figure 14). Note that, at early times of the propagation, the partial mixing between the dense liquid and water prevents the tracking of the invisible front of the currents.

At early times, the front position $x_{f}-x^{B}$ increases faster for larger $v$ (from light to dark gray symbols), due to the flow dynamics of the current in the near-field region. Then, at sufficiently long times, all experimental data collapse on a master curve with a linear trend (dashed line), regardless of $q$ and $v$. In contrast, at sufficiently low $v \lesssim$ $2.3 \mathrm{dm}^{2}$ (cross symbols, in inset of Figure 14), the front position deviates from the linear trend and tends towards a slope of $2 / 3$ (solid line). Surprisingly, the constant frontvelocities of both particle-driven gravity currents (black symbols, in Figure 14) and homogeneous gravity currents (blue circles, in inset of Figure 14) are similar for different $q$ and $v$. More specifically, one obtains $d x_{f} / d t \sim 0.35 \mathrm{~m} . \mathrm{s}^{-1}$ (dashed lines), which suggests that both currents have similar densities, and this point will be further discussed in the following.

Figure 15(a) shows the temporal evolution of the height $h$ of particle-driven gravity currents at $x \sim 3.5 \mathrm{~m}$. The height $h$ increases rapidly at the front and then remains roughly constant over time (dashed lines), despite Kelvin-Helmholtz instabilities at the interface. Moreover, the constant height of the current behind the front, noted $\langle h\rangle$, is only dependent on the water depth $H_{o}$, while the flow rate per unit width $q$, the volume per unit width $v$, and the slope angle $\theta$ are varied. In Figure $15(\mathrm{~b}),\langle h\rangle$ increases linearly 


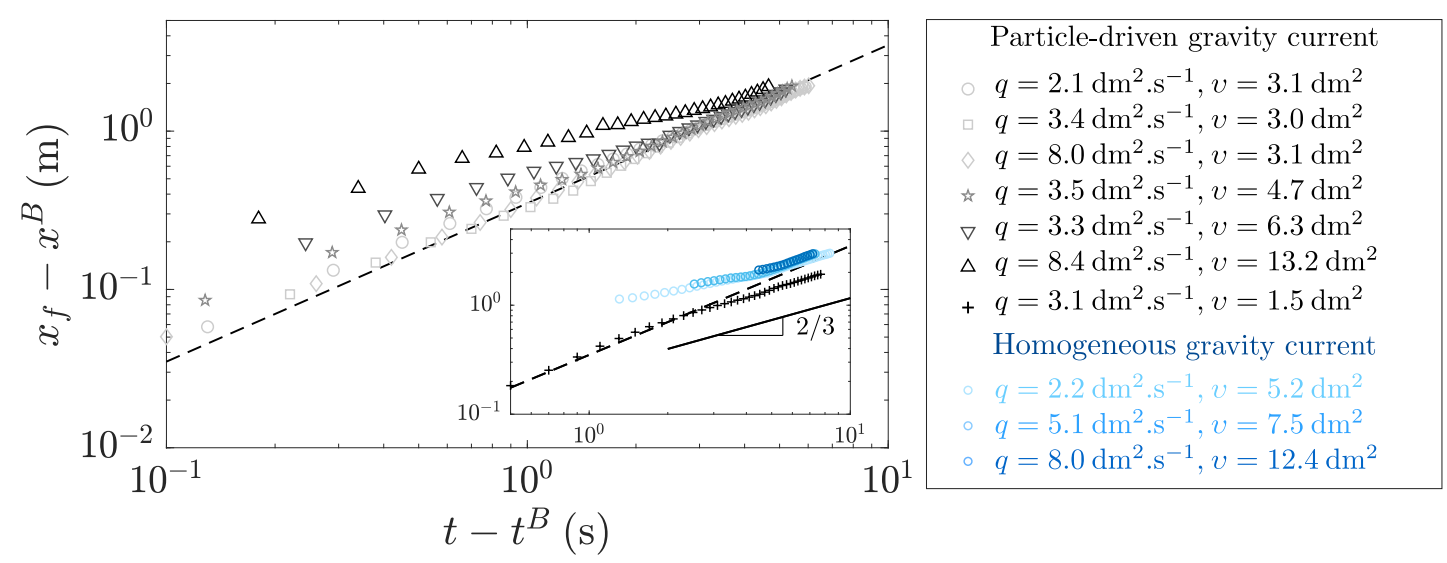

Figure 14. Far-field region: temporal evolution of the front position $x_{f}-x^{B}$ of the particledriven gravity currents (gray symbols) and homogeneous gravity currents (blue circles) as a function of time since arrival at the slope break, for different flow rates $q$ and volumes per unit width $v$. The water depth and the slope angle are set to $H_{o} \sim 26.5 \mathrm{~cm}$ and $\theta=15^{\circ}$, respectively. The dashed line is $x_{f}-x^{B}=0.35\left(t-t^{B}\right)$ and the solid line represents a slope of $2 / 3$.
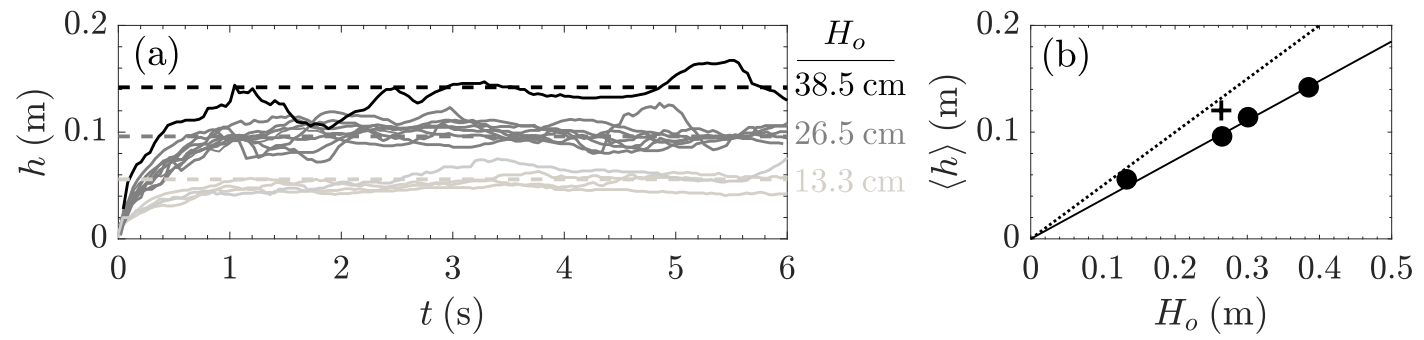

Figure 15. Far-field region: (a) Temporal evolution of the height $h$ of particle-driven gravity currents at $x \sim 3.5 \mathrm{~m}$, for different flow rates per unit width $q$ and volumes per unit width $v$ of the granular flow, water depths $H_{o}$ and slope angles $\theta$. Here, the time $t=0$ corresponds to the arrival time of the current front at the given position. The dashed lines indicate the constant height $\langle h\rangle$ of currents behind the front. (b) $\langle h\rangle$ as a function of $H_{o}$, for particle-driven gravity currents (full circles) and homogeneous gravity currents (cross). The lines are $\langle h\rangle=\gamma H_{o}$, with the best fit $\gamma=0.37$ (solid line) and the theoretical value $\gamma=0.5$ (dotted line) for homogeneous gravity currents in the full-depth lock-exchange, respectively.

with $H_{o}$, and in particular, it is found that $\langle h\rangle \sim 0.37 H_{o}$ (solid line). Note that $\langle h\rangle$ is slightly lower for particle-driven gravity currents (full circles) than for homogeneous gravity currents (cross), which could be attributed to the different mixing efficiencies at the interface. Finally, the dotted line represents the theoretical value $\langle h\rangle=0.5 H_{o}$, for homogeneous gravity currents in the full-depth lock-exchange (Ungarish, 2007; Bonometti \& Balachandar, 2010). Experimental data of both particle-driven and homogeneous gravity currents are lower than the theoretical prediction, which is partly consistent with other experimental studies (Rottman \& Simpson, 1983; Lowe et al., 2005). In particular, Lowe et al. (2005) showed that the decrease of the density ratio $\rho_{f} / \rho$ between the surrounding fluid and the current could decrease the parameter $\gamma$ (see their Figure 12), but it cannot fully explain the values obtained here. 
In view of these results, the motion of particle-driven gravity currents in the farfield region can be roughly related to that of homogeneous gravity currents in the fulldepth lock-exchange, far enough from the shoreline where the propagation in the nearfield region does not affect yet the front dynamics. In the present work, most of currents exhibit a constant height and velocity of the front similar to the slumping regime while, at low $v$, the front position evolves as $x_{f} \propto t^{2 / 3}$ according to the inertial self-similar regime. In both regimes, the preponderance of inertia over viscous effects can be quantified by the Reynolds number $R e=(\rho\langle h\rangle / \mu)\left(d x_{f} / d t\right)$, where $\rho \sim \rho_{f}$ and $\mu \sim \mu_{f}$ are the density and the viscosity of currents estimated as those of water given that the bulk particle concentration remains sufficiently low [see Figure 16(e)], and $\langle h\rangle$ and $d x_{f} / d t$ are the height and the front velocity of currents in the far-field region. The Reynolds number is in the range $R e=\left[10^{4}: 6 \times 10^{4}\right]$, much larger than one. Now, let us consider that the theoretical relation of the constant flow-front velocity, i.e. $d x_{f} / d t=0.5\left(g^{\prime \prime} H_{o}\right)^{1 / 2}$ with $g^{\prime \prime}=g\left(\rho-\rho_{f}\right) / \rho_{f}$, can be used here (Ungarish, 2007). It should be remembered that this relation is applicable as long as the settling of grains is sufficiently slow along the time and the particle concentration is not too high, i.e. $\phi \lesssim 0.3$ (Hallworth \& Huppert, 1998). These assumptions seem to be reasonable here because the constant front velocity of currents is broadly maintained until $x_{f}-x^{B} \sim 2 \mathrm{~m}$ corresponding to the tracked propagation, and the bulk particle concentration of the currents is thereafter estimated of the order of $\mathcal{O}(0.1)$ [Figure 16(e)]. Now, the above-mentioned equation of the front velocity can be reversed to estimate the bulk concentration of particle-driven gravity currents because the density and the concentration are related by $\rho=\phi \rho_{p}+(1-$ ф) $\rho_{f}$, where $\rho_{p}=2550 \mathrm{~kg} \cdot \mathrm{m}^{-3}$ and $\rho_{f}=1000 \mathrm{~kg} . \mathrm{m}^{-3}$ are the densities of grains and water, respectively. Recall that the bulk particle concentration of currents corresponds to $\phi=V_{\text {grains }} / V_{\text {current }}$, where $V_{\text {grains }}$ ans $V_{\text {current }}$ denote the volume of grains and the total volume of the current, respectively. In this way, one obtains

$$
\phi=\frac{4 \rho_{f}}{\left(\rho_{p}-\rho_{f}\right) g H_{o}}\left(\frac{d x_{f}}{d t}\right)^{2} .
$$

No clear trend is obtained between the bulk volume concentration of particles $\phi$ and the flow rate per unit width $q$, the volume per unit width $v$, and the water depth $H_{o}$, which suggests its independency on these different parameters [Figure 16(a)-(c)]. By contrast, the slope angle $\theta$ of the inclined plane seems to affect the concentration of currents, in the far-field region [Figure 16(d)]. More specifically, a steeper slope angle $\theta$ of the inclined plane promotes a larger bulk particle concentration of currents. Now, regardless of the role of $\theta$, the bulk concentration of particle-driven gravity currents is roughly constant in the set of experiments, with an order of magnitude of $\phi \sim \mathcal{O}(0.1)$ [Figure 16(e)]. More precisely, it is found that $\phi \sim 0.13 \pm 0.035$ (dashed line and gray area), but some caution has to be exercised with the obtained value because some crude assumptions were made through the model. This result suggests, however, that an increase of the front velocity, the front height, or the volume of the granular flow do not increase the bulk particle concentration $\phi$ of the currents interpreted as a critical value. This critical value of $\phi$ corresponds to a current density of $\rho \sim 1.20 \pm 0.09$ g.cm ${ }^{-3}$, similar to that of homogeneous gravity currents in our experiments. This could explain that the front-velocity of both particle-driven and homogeneous gravity currents is similar in the far-field region (see Figure 14). Moreover, the constant value of $\phi$ supports the idea that the relative gravity can be disregarded using Britter and Linden's scaling in the nearfield region (see Figure 13). Finally, Freundt (2003) also estimated the density of particledriven gravity currents generated by experimental volcanic ash flows entering water based on the front dynamics of the currents. He reported a bulk density of currents evolving from $\rho \sim 1.15-1.25 \mathrm{~g} . \mathrm{cm}^{-3}$ proximally to $<1.01 \mathrm{~g} . \mathrm{cm}^{-3}$ near the tank end, corresponding to bulk particle concentrations from $0.16-0.27$ proximally to 0.01 distally. The strong decrease of the particle concentration along the current propagation is at- 


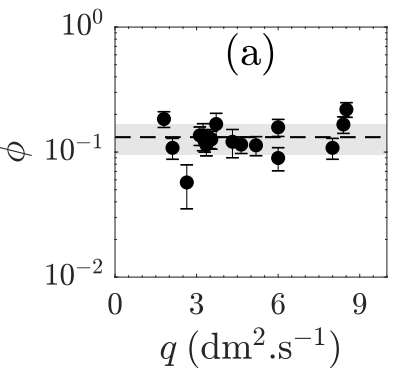
properties (e.g., size, density, shape).
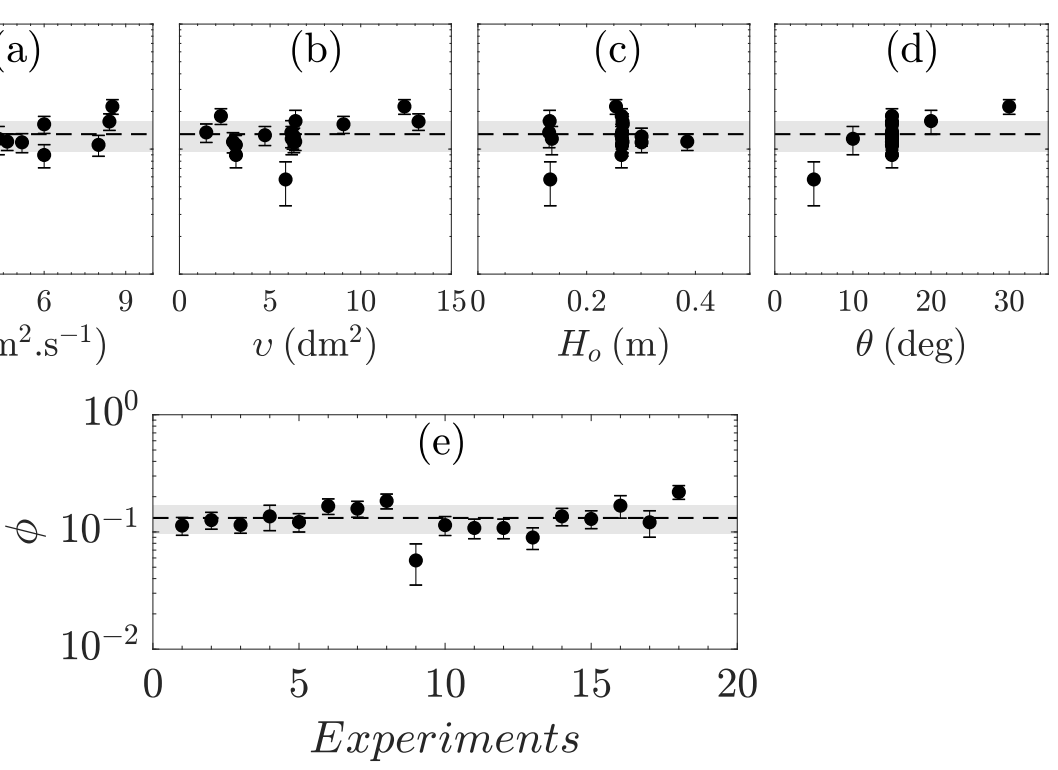

tributed to the high settling velocity of the ash material sieved at $4 \mathrm{~mm}$, which is much smaller in our experiments with glass beads of $65 \mu \mathrm{m}$. In both cases, the bulk particle concentration of currents proximally is estimated to be of the same order of magnitude, i.e. $\phi \sim 0.16-0.27$ for Freundt (2003)'s experiments and $\phi \sim 0.13 \pm 0.035$ for our experiments, while quantitative variations can be probably attributed to the different grain

Figure 16. Bulk particle concentration $\phi$ (in volume) of particle-driven gravity currents estimated by equation (5) in the far-field region, as a function of (a) the flow rate per unit width $q$, (b) the volume per unit width $v$, (c) the water depth $H_{o}$, (d) the slope angle $\theta$ of the inclined plane, and (e) for all experiments of the present study. The dashed line and gray area correspond to the mean value and the standard deviation, i.e. $\phi \sim 0.13 \pm 0.035$.

\subsection{Discussion of results}

In the natural environment, there are few measurements of particle concentration in subaqueous particle-laden flows due to the difficulty of predicting them. For turbidity currents in which grains are mainly suspended by the turbulent fluid, available field measurements showed that the volume concentration was usually lower than 0.01 (Talling et al., 2013, and references herein). The indirect concentration measurements of submarine currents caused by the 1929 Grand Banks event, however, give higher values of 0.03-0.05 (Stevenson et al., 2018). Moreover, recent works reported that the dilute clouds of such currents can sometimes overlay dense basal layers (Paull et al., 2018; Simmons et al., 2020; Wang et al., 2020). In fact, grains can theoretically be suspended by the fluid turbulence up to a volume concentration of about 0.1 , above which grains settle due to the importance of grain-grain interaction (Bagnold, 1962). This threshold is in line with the critical concentration obtained in our experiments, while other experimental studies also observed a threshold of the particle concentration in fluid-particle systems.

For the purpose of better understanding subaerial dilute pyroclastic density currents, Weit et al. $(2018,2019)$ performed experiments to study the spatial distribution of solid grains into a gas-particle turbulent system. In a steady vertical flow in which grains were poured gradually, the bulk particle concentration of the dilute gas-particle suspen- 
sion increased with the added granular mass before it reached a threshold. Then, the excess of grains could not be suspended by the turbulent fluid and clusters were formed and fell forming a basal concentrated granular bed. The coexistence of dilute and dense regions controlled by clustering instabilities has also been observed for gas-particle gravitydriven flows, which suggested that the upper dilute part was in its saturated-state (Breard et al., 2016). Although clustering is poorly understood, it is usually attributed to dissipation of the granular temperature by collisional contacts or to hydrodynamic instabilities caused by the relative motion between the grains and the surrounding fluid (more details in Fullmer \& Hrenya, 2017, and references herein). In both above-mentioned experiments, the critical volume concentration of the dilute region was a few percent, much lower than in our experiments. Yet, subaerial pyroclastic density currents and subaqueous turbidity currents share common characteristics, such as the turbulent-multiphase nature and the potential formation of dense granular regions (Doronzo \& Dellino, 2010). For grains suspended in water by a vertical oscillating grid, the particle concentration also saturated to a critical value depending on the oscillation frequency, but the clustering instabilities disappeared (Bennett et al., 2013, 2014).

In view of these findings, the particle-driven gravity currents in our experiments could be related to physical mechanisms similar to those mentioned above. The impact between the granular flow and water generated a turbulent mixing zone, in which grains were suspended by the turbulent fluid. The bulk volume concentration of particles exceeded a critical value, leading to a saturated upper region in which the excess of grains probably fell, forming a basal concentrated region. For all experiments, a thick and voluminous granular deposit was obtained along the inclined plane, which could be interpreted as the final state of the dense granular flow (see Figure 6). Unfortunately, the flow dynamics of the dense basal region cannot be observed directly because of the visual limitations of the optical shadowgraph method. Under the influence of gravity, the upper dilute suspension at critical particle concentration collapsed on the inclined plane forming the particle-driven gravity current. Compared to gas-particle turbulent systems with critical volume concentrations less than $\sim 0.03-0.04$, the high value of the critical concentration observed here could be attributed to different grain-fluid interaction. It is probable that the clustering instabilities control the critical concentration of gas-particle flows, in response to different settling rates between individual particles and clusters. This physical mechanism is mainly controlled by the grain inertia through the Stokes number, which is usually defined as the ratio between the particle inertial response time and the turbulent timescale (Warhaft, 2009). For liquid-particle systems, however, further work will be necessary to highlight the physical mechanisms controlling the critical concentration of particles.

\section{Conclusion}

Well-controlled laboratory experiments focusing on the entrance of gas-fluidized granular flows into water have been performed, and backed up by theoretical models, to understand better the motion of geophysical granular flows going down a mountainside, then entering the sea, a lake or a river, and finally progagating underwater for what can be a considerable distance. The consideration of fluidized granular flows ensured a more suitable modelling of highly-mobile fine-grained geophysical flows, which are predisposed to reach the coast and generate turbidity currents. First, the presence of a water body promoted the generation of a granular jet over the free-surface, a leading and largest wave, and a turbulent mixing zone from which a particle-driven gravity current was spontaneously formed. Overall, hydrodynamic forces played a dissipative role by slowing and reducing the spreading of the granular mass along the bottom plane. However, a low amount of grains were still transported by the turbulent fluid like a gravity current propagating far away, showing both the dissipative and driving role of the fluid. Then, the granular jet and the particle-driven gravity current were analyzed by tracking the spatio-temporal 
evolution of the jet crest and the current front, respectively. The trajectory of the granular jet was well described by the theoretical prediction of frictionless ballistic motion, for which the initial parameters of the model depended on the flow-front velocity and the slope angle of the inclined plane. The flow dynamics of particle-driven gravity currents was described in two distinguished regions beneath the water surface, namely along the inclined plane and the horizontal plane, referred to as the near- and far-field regions, respectively. In the near-field region, the propagation of the current mainly depended on the flow rate per unit width $q$ and the temporal evolution of the front position scaled with time as $x_{f} \sim(g q)^{1 / 3} t$, with $g$ the gravitational acceleration, in agreement with earlier findings. Then, the granular inflow was stopped and the finite volume affected the motion of the current from the above-mentioned scaling. In the far-field region, the evolution of the front position was similar to that of homogeneous gravity currents in the full-depth lock-exchange configuration. The particle-driven gravity current first evolved with a constant-front velocity in the so-called slumping regime, then the front decelerated and its position scaled as $x_{f} \sim t^{2 / 3}$ in the inertial self-similar regime. During the slumping regime, the constant flow-front velocity was only controlled by the height of the current depending on the water depth. More specifically, the bulk particle concentration of the current was roughly constant, i.e. $\phi \sim 0.13 \pm 0.035$ (in volume), in the range of parameters considered. This result is interpreted as a critical concentration reached in turbulent fluid-particle flows, above which the excess of particles cannot be maintained by the turbulent fluid.

This study provides the conclusions that highly mobile fine-grained geophysical flows entering water are predisposed to generate granular jets above the free surface and dilute particle-driven gravity currents underwater. Both can be fairly well predicted using simple theoretical models capturing most of the physical mechanisms, which are of interest for geophysical purposes. Lastly, the bulk particle concentration of gravity currents generated by rapid granular flows entering water reaches a threshold, which needs further work to investigate the influence of grains properties (e.g., density, diameter) and to support this outcome by direct measurements.

\section{Acknowledgments}

This work was funded by the ANR RAVEX (ANR-16-CE03-0002) project. The authors acknowledge the technical support of the Laboratoire Magmas et Volcans (Marc Nivoix, Eric Brut, Jean-Louis Fruquière, Cyrille Guillot) for their contribution in designing and constructing the experimental setup. We thank the anonymous reviewers for their constructive comments that helped to improve the initial manuscript. This is ClerVolc contribution $\mathrm{n}^{\circ} 470$. Data presented in this paper are partly in open access at https://doi.org/10.6084/m9.figshare.12137373

\section{References}

Allen, S. R., Freundt, A., \& Kurokawa, K. ～(2012). Characteristics of submarine pumice-rich density current deposits sourced from turbulent mixing of subaerial pyroclastic flows at the shoreline: field and experimental assessment. Bull. Volcanol., 74, 657-675.

Ancey, C., Iverson, R. M., Rentschler, M., \& Denlinger, R. P. (2008). An exact solution for ideal dam-break floods on steep slopes. Water Resour. Res., 44, W01430.

Bagnold, R. A. (1962). Auto-suspension of transported sediment: turbidity currents. Proc. Roy. Soc. London A, 265, 315-319.

Baines, P. (2001). Mixing in flows down gentle slopes into stratified environments. $J$. Fluid Mech., 443, 237-270.

Baines, P. (2005). Mixing regimes for the flow of dense fluid down slopes into stratified environments. J. Fluid Mech., 538, 245-267. 
Beghin, P., Hopfinger, E. J., \& Britter, R. E. (1981). Gravitational convection from instantaneous sources on inclined boundaries. J. Fluid Mech., 107, 407-422.

Bennett, S. J., Atkinson, J. F., Hou, Y., \& Fay, M. J. (2013). Turbulence modulation by suspended sediment in a zero mean-shear geophysical flow. Coherent Flow Structures at Earth's Surface, 309-321.

Bennett, S. J., Hou, Y., \& Atkinson, J. F. (2014). Turbulence suppression by suspended sediment within a geophysical flow. Envion. Fluid Mech., 14, 771-794.

Bonnecaze, R. T., Hallworth, M. A., Huppert, H. E., \& Lister, J. R. (1995). Axisymmetric particle-driven gravity currents. J. Fluid Mech., 294, 93-121.

Bonnecaze, R. T., Huppert, H. E., \& Lister, J. R. (1993). Particle-driven gravity currents. J. Fluid Mech., 250, 339-369.

Bonometti, T., \& Balachandar, S. (2010). Slumping of non-Boussinesq density currents of various initial fractional depths: a comparison between direct numerical simulations and a recent shallow-water model. Comput. Fluids, 39(4), 729-734.

Bonometti, T., Balachandar, S., \& Magnaudet, J. (2008). Wall effects in nonBoussinesq density currents. J. Fluid Mech., 616, 445-475.

Bougouin, A., Lacaze, L., \& Bonometti, T. (2017). Collapse of a neutrally buoyant suspension column: from Newtonian to apparent non-Newtonian flow regimes. J. Fluid Mech., 826, 918-941.

Bougouin, A., Paris, R., \& Roche, O. (2019). Ecoulement granulaire fluidisé impactant l'eau: Application aux tsunamis volcaniques. 24ème Congrès français de mécanique, Brest, France.

Bougouin, A., Paris, R., \& Roche, O. (2020). Impact of fluidized granular flows into water: Implications for tsunamis generated by pyroclastic flows. J. Geophys. Res. Solid Earth, 125, e2019JB018954.

Bowden, F. P., \& Hughes, T. P. (1939). The mechanism of sliding on ice and snow. Proc. of the Royal Society of London. Series A., 172, 280-298.

Breard, E. C. P., Lube, G., Jones, J. R., Dufek, J., Cronin, S. J., Valentine, G. A., \& Moebis, A. (2016). Coupling of turbulent and non-turbulent flow regimes within pyroclastic density currents. Nat. Geosci., 9, 767-771.

Britter, R. E., \& Linden, P. F. (1980). The motion of the front of a gravity current travelling down an incline. J. Fluid Mech., 99, 531-543.

Brodu, N., Delannay, R., Valance, A., \& Richard, P. (2015). New patterns of highspeed granular flows. J. Fluid Mech., 769, 218-228.

Bullard, G. K., Mulligan, R. P., Carreira, A., \& Take, W. A. (2019). Experimental analysis of tsunamis generated by the impact of landslides with high mobility. Coast. Eng., 152, 103538.

Cas, R. A. F., \& Wright, J. V. (1991). Subaqueous pyroclastic flows and ignimbrites: an assessment. Bull. Volcanol., 53, 357-380.

Clous, L., Le Guer, Y., \& Abbadie, S. (2019). Génération de vagues par des coulées liquides : application aux écoulements pyroclastiques. 24ème Congrès français de mécanique, Brest, France.

Collins, G. S., \& Melosh, H. J. (2003). Acoustic fluidization and the extraordinary mobility of sturzstroms. J. Geophys. Res., 108, 2473-2487.

Cortés, A., Rueda, F. J., \& Wells, M. G. (2014). Experimental observations of the splitting of a gravity current at a density step in a stratified water body. $J$. Geophys. Res. Oceans, 119, 1038-1053.

Dai, A. (2013). Experiments on gravity currents propagating on different bottom slopes. J. Fluid Mech., 731, 117-141.

Dai, A. (2014). Non-Boussinesq gravity currents propagating on different bottom slopes. J. Fluid Mech., 741, 658-680.

Dai, A., \& Garcia, M. (2010). Gravity currents down a slope in deceleration phase. Dyn. Atmos. Oceans, 49. 
Davies, T. R., \& McSaveney, M. J. (2009). The role of rock fragmentation in the motion of large landslides. Eng. Geol., 109, 67-79.

Davies, T. R. H. (1982). Spreading of rock avalanche debris by mechanical fluidization. Rock Mech., 15, 9-24.

De Blasio, F. V., Elverhoi, A., Engvik, L. E., Issler, D., Gauer, P., \& Harbitz, C. (2006). Understanding the high mobility of subaqueous debris flows. Nor. J. Geol., 86, 275-284.

Delannay, R., Valance, A., Mangeney, A., Roche, O., \& Richard, P. (2017). Granular and particle-laden flows: from laboratory experiments to field observations. $J$. Phys. D, 50, 053001.

Doronzo, D. M., \& Dellino, P. (2010). A fluid dynamic model of volcaniclastic turbidity currents based on the similarity with the lower part of dilute pyroclastic density currents: evaluation of the ash dispersal from ash turbidites. $J$. Volcanol. Geotherm. Res., 191, 193-204.

Dressler, R. F. (1954). Comparison of theories and experiments for the hydraulic dam-break wave. Int. Assoc. Sci. Hydrology, 3, 319-328.

Edmonds, M., \& Herd, R. A. (2005). Inland-directed base surge generated by the explosive interaction of pyroclastic flows and sea water at Soufrière Hills volcano, Montserrat. Geology, 33, 245-248.

Farin, M., Mangeney, A., \& Roche, O. (2014). Fundamental changes of granular flow dynamics, deposition, and erosion processes at high slope angles: Insights from laboratory. J. Geophys. Res., 119, 504-532.

Freundt, A. (2003). Entrance of hot pyroclastic flows into the sea: Experimental observations. Bull. Volcanol., 65, 144-164.

Fritz, H. M., Hager, W. H., \& Minor, H.-E. (2003a). Landslide generated impulse waves. 1. Instantaneous flow fields. Exp. Fluids, 35, 505-519.

Fritz, H. M., Hager, W. H., \& Minor, H.-E. (2003b). Landslide generated impulse waves. 2. Hydrodynamic impact craters. Exp. Fluids, 35, 520-532.

Fullmer, W. D., \& Hrenya, C. M. (2017). The clustering instability in rapid granular and gas-solid flows. Annu. Rev. Fluid Mech., 49, 485-510.

Giudicepietro, F., López, C., Macedonio, G., Alparone, S., Bianco, F., Calvari, S., ... Tramelli, A. (2020). Geophysical precursors of the July-August 2019 paroxysmal eruptive phase and their implications for Stromboli volcano (Italy) monitoring. Sci. Rep., 10, 1-16.

Goren, L., \& A., E. (2007). Long runout landslides: the role of frictional heating and hydraulic diffusivity. Geophys. Res. Lett., 34, L07301.

Hallworth, M. A., \& Huppert, H. E. (1998). Abrupt transitions in highconcentration, particle-driven gravity currents. Phys. Fluids, 10, 1083-1087.

Heezen, B. C., \& Ewing, M. (1952). Turbidity currents and submarine slumps, and the 1929 Grand Banks earthquake. Am. J. Sci., 250, 849-873.

Heezen, B. C., \& Ewing, M. (1955). Orleansville earthquake and turbidity currents. AAPG Bull., 39, 2505-2514.

Heller, V., Hager, W. H., \& Minor, H.-E. (2008). Scale effects in subaerial landslide generated impulse waves. Exp. Fluids, 44, 691-703.

Hsu, S.-K., Kuo, J., Chung-Liang, L., Ching-Hui, T., Doo, W.-B., Ku, C.-Y., \& Sibuet, J.-C. (2008). Turbidity currents, submarine landslides and the 2006 Pingtung earthquake off SW Taiwan. Terr. Atmos. Ocean Sci., 19, 767-772.

Hungr, O., \& Evans, S. G. (2004). Entrainment of debris in rock avalanches: an analysis of a long run-out mechanism. Geol. Soc. Am. Bull., 116, 1240-1252.

Huppert, H. E. (1982). The propagation of two-dimensional and axisymmetric viscous gravity currents over a rigid horizontal surface. J. Fluid Mech., 121, 4358.

Huppert, H. E., \& Simpson, J. E. (1980). The slumping of gravity currents. J. Fluid Mech., 99, 785-799. 
Jánosi, I. M., Jan, D., Szabó, K. G., \& Tél, T. (2004). Turbulent drag reduction in dam-break flows. Exp. Fluids, 37, 219-229.

Kneller, B., \& Buckee, C. (2000). The structure and fluid mechanics of turbidity currents: a review of some recent studies and their geological implications. Sedimentology, 47, 62-94.

Kokelaar, P., \& Busby, C. (1992). Subaqueous explosive eruption and welding of pyroclastic deposits. Science, 257, 196-201.

Laubert, G., \& Hager, W. H. (1998). Experiments to dambreak wave: Horizontal channel. J. Hydraul. Res., 36, 291-307.

Leal, J. G., Ferreira, R. M., \& Cardoso, A. H. (2006). Dam-break wave-front velocity. J. Hydraul. Res., 132, 69-76.

Le Friant, A., Deplus, C., Boudon, G., Feuillet, N., Trofimovs, J., Komorowski, J.-C., ... Ryan, G. (2010). Eruption of Soufrière Hills (1995-2009) from an offshore perspective: Insights from repeated swath bathymetry surveys. Geophys. Res. Lett., 37.

Le Friant, A., Deplus, C., Boudon, G., Sparks, R. S. J., Trofimovs, J., \& Talling, P. (2009). Submarine deposition of volcaniclastic material from the 1995-2005 eruptions of Soufrière Hills volcano, Montserrat. J. Geol. Soc., 166, 171-182.

Legros, F., \& Druitt, T. H. (2000). On the emplacement of ignimbrite in shallowmarine environments. J. Volcanol. Geotherm. Res., 95, 9-22.

Løvholt, F., Pedersen, G., Harbitz, C. B., Glimsdal, S., \& Kim, J. (2015). On the characteristics of landslide tsunamis. Phil. Trans. R. Soc. A, 373, 20140376.

Lowe, R. J., Rottman, J. W., \& Linden, P. F. (2005). The non-Boussinesq lockexchange problem. Part 1. Theory and experiments. J. Fluid Mech., 537, 101124.

Major, J. J., \& Iverson, R. M. (1999). Debris-flow deposition: Effects of pore-fluid pressure and friction concentrated at flow margins. Geol. Soc. Am. Bull., 111, $1424-1434$.

Mangeney, A., Roche, O., Hungr, O., Mangold, N., Faccanoni, G., \& Lucas, A. (2010). Erosion and mobility in granular collapse over sloping beds. J. Geophys. Res., 115, F03040.

Mazzanti, P., \& De Blasio, F. V. (2011). The dynamics of coastal landslides: Insights from laboratory experiments and theoretical analyses. Bull. Eng. Geol. Environ., 70, 411-422.

Mcleod, P., Carey, S., \& Sparks, R. S. J. (1999). Behaviour of particle-laden flows into the ocean: experimental simulation and geological implications. Sedimentology, 46, 523-536.

Meiburg, E., \& Kneller, B. (2010). Turbidity currents and their deposits. Annu. Rev. Fluid Mech., 42, 135-156.

Melosh, H. J. (1979). Acoustic fluidization: A new geologic process? J. Geophys. Res, 84, 7513-7520.

Miller, G. S., Andy T., W., Mulligan, R. P., \& McDougall, S. (2017). Tsunamis generated by long and thin granular landslides in a large flume. J. Geophys. Res., 122, 653-668.

Monaghan, J. J. (2007). Gravity current interaction with interfaces. Annu. Rev. Fluid Mech., 39, 245-261.

Monaghan, J. J., Cas, R. A. F., Kos, A. M., \& Hallworth, M. (1999). Gravity currents descending a ramp in a stratified tank. J. Fluid Mech., 379.

Mulder, T., Savoye, B., \& Syvitski, J. P. M. (1997). Numerical modelling of a mid-sized gravity flow: the 1979 Nice turbidity current (dynamics, processes, sediment budget and seafloor impact). Sedimentology, 44, 305-326.

Paull, C. K., Talling, P. J., Maier, K. L., Parsons, D., Xu, J., Caress, D. W., ... Cartigny, M. J. (2018). Powerful turbidity currents driven by dense basal layers. Nat. Commun., 9, 1-9. 
Ritter, A. (1892). Die fortpflanzung der wasserwellen. Z. Verein Deutch. Ing., 36 , 947-954.

Roche, O., Montserrat, S., Niño, Y., \& Tamburrino, A. (2008). Experimental observations of water-like behavior of initially fluidized, dam break granular flows and their relevance for the propagation of ash-rich pyroclastic flows. $J$. Geophys. Res., 113, B12203.

Rottman, J. W., \& Simpson, J. E. (1983). Gravity currents produced by instantaneous releases of a heavy fluid in a rectangular channel. J. Fluid Mech., 135, $95-110$.

Shreve, R. L. (1968). Leakage and fluidization in air-layer lubricated avalanches. Geol. Soc. Am. Bull., 79, 653-658.

Simmons, S. M., Azpiroz-Zabala, M., Cartigny, M. J. B., Clare, M. A., Cooper, C., Parsons, D. R., ... Talling, P. J. (2020). Novel acoustic method provides first detailed measurements of sediment concentration structure within submarine turbidity currents. J. Geophys. Res. Oceans, 125, e2019JC015904.

Sovilla, B., Burlando, P., \& Bartelt, P. (2006). Field experiments and numerical modeling of mass entrainment in snow avalanches. J. Geophys. Res.: Earth Surface, 111, F03007.

Sparks, R. S. J. (1976). Grain size variations in ignimbrites and implications for the transport of pyroclastic flows. Sedimentology, 23, 147-188.

Sparks, R. S. J., Sigurdsson, H., \& Carey, S. (1980). The entrance of pyroclastic flows into the sea. II. Theoretical considerations on subaqueous emplacement and welding. J. Volcanol. Geotherm. Res., 7, 97-105.

Stevenson, C. J., Feldens, P., Georgiopoulou, A., Schönke, M., Krastel, S., Piper, D. J. W., ... Mosher, D. (2018). Reconstructing the sediment concentration of a giant submarine gravity flow. Nat. Commun., 9, 1-7.

Talling, P. J., Paull, C. K., \& Piper, D. J. W. (2013). How are subaqueous sediment density flows triggered, what is their internal structure and how does it evolve? Direct observations from monitoring of active flows.

Earth Sci. Rev., 125, 244-287.

Talling, P. J., Wynn, R. B., Masson, D. G., Frenz, M., Cronin, B. T., Schiebel, R., ... Amy, L. A. (2007). Onset of submarine debris flow deposition far from original giant landslide. Nature, 450, 541-544.

Trofimovs, J., Amy, L., Boudon, G., Deplus, C., Doyle, E., Fournier, N., ... Talling, P. J. (2006). Submarine pyroclastic deposits formed at the Soufrière Hills volcano, Montserrat (19952003): What happens when pyroclastic flows enter the ocean? Geology, 34, 549-552.

Trofimovs, J., Foster, C., Sparks, R. S. J., Loughlin, S., Le Friant, A., Deplus, C., ... Le Bas, T. (2012). Submarine pyroclastic deposits formed during the 20th May 2006 dome collapse of the Soufrière Hills Volcano, Montserrat. Bull. Volcanol., $74,391-405$.

Trofimovs, J., Sparks, R. S. J., \& Talling, P. J. (2008). Anatomy of a submarine pyroclastic flow and associated turbidity current: July 2003 dome collapse, Soufrière Hills volcano, Montserrat, West Indies. Sedimentology, 55, 617-634.

Ungarish, M. (2007). A shallow-water model for high-Reynolds-number gravity currents for a wide range of density differences and fractional depths. J. Fluid Mech., 579, 373-382.

Viroulet, S., Sauret, A., \& Kimmoun, O. (2014). Tsunami generated by a granular collapse down a rough inclined plane. EPL, 105, 34004.

Wadge, G., Voight, B., Sparks, R. S. J., Cole, P. D., Loughlin, S. C., \& Robertson, R. E. A. (2014). An overview of the eruption of Soufriere Hills volcano, Montserrat from 2000 to 2010. Geol. Soc. Lond. Mem., 39, 1-40.

Wang, Z., Xu, J., Talling, P. J., Cartigny, M. J. B., Simmons, S. M., Gwiazda, R., ... Parsons, D. R. (2020). Direct evidence of a high-concentration basal layer in a submarine turbidity current. Deep Sea Res. Part I, 103300. 
Warhaft, Z. (2009). Laboratory studies of droplets in turbulence: towards understanding the formation of clouds. Fluid Dyn. Res., 41, 011201.

Weiss, R., Fritz, H. M., \& Wünnemann, K. (2009). Hybrid modeling of the megatsunami runup in Lituya Bay after half a century. Geophys. Res. Lett., 36, L09602.

Weit, A., Roche, O., Dubois, T., \& Manga, M. (2018). Experimental measurement of the solid particle concentration in geophysical turbulent gas-particle mixtures. J. Geophys. Res., 123, 3747-3761.

Weit, A., Roche, O., Dubois, T., \& Manga, M. (2019). Maximum solid phase concentration in geophysical turbulent gasparticle flows: Insights from laboratory experiments. Geophys. Res. Lett., 46, 6388-6396.

Wells, M. G., \& Dorell, R. M. (2020). Turbulence processes within turbidity currents. Annu. Rev. Fluid Mech., 53, 59-83.

Wells, M. G., \& Wettlaufer, J. S. (2007). The long-term circulation driven by density currents in a two-layer stratified basin. J. Fluid Mech., 572, 37-58.

Whitham, A. G. (1989). The behaviour of subaerially produced pyroclastic flows in a subaqueous environment: evidence from the Roseau eruption, Dominica, West Indies. Mar. Geol., 86, 27-40.

Young, S. R., Sparks, R. S. J., Aspinall, W. P., Lynch, L. L., Miller, A. D., Robertson, R. E. A., \& Shepherd, J. B. (1998). Overview of the eruption of Soufriere Hills volcano, Montserrat, 18 July 1995 to December 1997. Geophys. Res. Lett., 25, 3389-3392.

Zgheib, N., Bonometti, T., \& Balachandar, S. (2015). Dynamics of non-circular finite-release gravity currents. J. Fluid Mech., 783, 344-378.

Zhu, S. J., Zgheib, N., Balachandar, S., \& Ooi, A. (2017). Front dynamics of elliptical gravity currents on a uniform slope. Phys. Rev. Fluids, 2, 064801.

Zitti, G., Ancey, C., Postacchini, M., \& Brocchini, M. (2016). Impulse waves generated by snow avalanches: Momentum and energy transfer to a water body. $J$. Geophys. Res., 121, 2399-2423. 